\title{
Early intracellular trafficking of Waddlia chondrophila in human macrophages
}

\begin{abstract}
Correspondence
Gilbert Greub

gilbert.greub@chuv.ch
\end{abstract}

Received 11 September 2009

Revised 30 October 2009

Accepted 17 November 2009

\author{
Antony Croxatto and Gilbert Greub
}

Center for Research on Intracellular Bacteria (CRIB), Institute of Microbiology, University Hospital Center and University of Lausanne, 1011 Lausanne, Switzerland

\begin{abstract}
Waddlia chondrophila is an obligate intracellular bacterium considered as a potential agent of abortion in both humans and bovines. This member of the order Chlamydiales multiplies rapidly within human macrophages and induces lysis of the infected cells. To understand how this Chlamydia-like micro-organism invades and proliferates within host cells, we investigated its trafficking within monocyte-derived human macrophages. Vacuoles containing W. chondrophila acquired the early endosomal marker EEA1 during the first 30 min following uptake. However, the live $W$. chondrophila-containing vacuoles never co-localized with late endosome and lysosome markers. Instead of interacting with the endosomal pathway, W. chondrophila immediately colocalized with mitochondria and, shortly after, with endoplasmic reticulum- (ER-) resident proteins such as calnexin and protein disulfide isomerase. The acquisition of mitochondria and ER markers corresponds to the beginning of bacterial replication. It is noteworthy that mitochondrion recruitment to $W$. chondrophila inclusions is prevented only by simultaneous treatment with the microtubule and actin cytoskeleton-disrupting agents nocodazole and cytochalasin D. In addition, brefeldin $A$ inhibits the replication of $W$. chondrophila, supporting a role for COPI-dependent trafficking in the biogenesis of the bacterial replicating vacuole. W. chondrophila probably survives within human macrophages by evading the endocytic pathway and by associating with mitochondria and the ER. The intracellular trafficking of $W$. chondrophila in human macrophages represents a novel route that differs strongly from that used by other members of the order Chlamydiales.
\end{abstract}

\section{INTRODUCTION}

Waddlia chondrophila is a bacterium that belongs to the family Waddliaceae in the order Chlamydiales (Everett et al., 1999), which also includes the families Chlamydiaceae, Parachlamydiaceae, Simkaniaceae, 'Criblamydiaceae' and 'Rhabdochlamydiaceae' (Corsaro \& Greub, 2006). Members of the order Chlamydiales are obligate intracellular bacteria that replicate within eukaryotic cells of different origins including humans, animals and amoebae (Corsaro \& Greub, 2006; Horn, 2008). Members of the Chlamydiales are characterized by a biphasic development cycle comprising infectious, metabolically inactive elementary bodies (EB) and non-infectious, metabolically active, replicating reticulate bodies (RB) (Moulder, 1991). Many members of the Chlamydiales have been recognized as human pathogens.

$W$. chondrophila is an emerging pathogen. It has been isolated twice independently from aborted bovine fetuses (Henning et al., 2002; Rurangirwa et al., 1999), and

Abbreviations: BCV, bacteria-containing vacuole; BFA, brefeldin $A$; $E B$, elementary body; EEA1, early endosome antigen 1; ER, endoplasmic reticulum; PBMC, peripheral blood mononuclear cell; PDI, protein disulfide isomerase; $\mathrm{RB}$, reticulate body. serological studies indicate a role in ruminant (DilbeckRobertson et al., 2003) and human (Baud et al., 2007) abortion. In bovines, abortion could be reproduced by experimentally infecting pregnant cows (DilbeckRobertson et al., 2003; Henning et al., 2002). In humans, a strong association between miscarriage and the presence of anti- $W$. chondrophila antibodies was observed (Baud et al., 2007). The seroprevalence was higher in patients with sporadic (31.9\%) and recurrent (33\%) miscarriage than in patients with an uneventful pregnancy $(7.1 \% ; P<0.001)$ (Baud et al., 2007). Interestingly, W. chondrophila seropositivity was associated with animal contacts in this study, suggesting that these bacteria may be zoonotically transmitted. Hence, taken together, these results strongly suggest that $W$. chondrophila might be a causative agent of miscarriage in humans.

Virtually nothing is known about the pathogenesis or biology of $W$. chondrophila. To fill this gap, we investigated how this obligate intracellular bacterium survives and proliferates within human host cells. We have shown that $W$. chondrophila enters and multiplies rapidly within human macrophages, inducing lysis of infected cells (Goy et al., 2008). Since macrophages are one of the major 
components of the innate immune response that efficiently remove invading bacteria, the ability of $W$. chondrophila to resist the microbicidal effectors of macrophages suggests indirectly the possible human pathogenicity of this microorganism. However, the strategy used by $W$. chondrophila to resist destruction by macrophages is unknown, and is probably related to subversion of the endocytic pathway to avoid bacterial lysis within phagolysosomes (Duclos \& Desjardins, 2000).

In this work, we studied the early intracellular trafficking of $W$. chondrophila in monocyte-derived human macrophages as a primary stage to understand the molecular mechanisms that govern the interactions of $W$. chondrophila with host cells.

\section{METHODS}

Bacterial strains. W. chondrophila ATCC VR-1470 ${ }^{\mathrm{T}}$ and Parachlamydia acanthamoebae strain Hall's coccus were grown at $32{ }^{\circ} \mathrm{C}$ within Acanthamoeba castellanii in $75 \mathrm{~cm}^{2}$ cell-culture flasks (Corning) with $30 \mathrm{ml}$ peptone-yeast extract-glucose broth (Greub \& Raoult, 2002). After 6 days of incubation, cultures were harvested and the broth was filtered through a $5 \mu \mathrm{m}$-pore membrane to eliminate both amoebal trophozoites and cysts and to collect bacteria in the flow-through.

Antibodies, probes and reagents. Mouse monoclonal antibody against protein disulfide isomerase (PDI; sc-59649), early endosome antigen 1 (EEA1; sc-53939) and KDEL endoplasmic reticulum (ER) marker (10C3; sc-58774) were purchased from Santa Cruz Biotechnology. Mouse polyclonal antibody against GM130 (610822) and mouse monoclonal antibody against Lamp-1 (CD107a; 555798) were obtained from BD Biosciences. Rabbit polyclonal antibody against calnexin (SPA-860) was purchased from Stressgen. Mouse anti-v-ATPase (OSW2) was a kind gift of Dr Satoshi B. Sato (Kyoto University, Japan). The fluorescent probes LysoTracker Red DND-99 (L7528) and MitoTracker Red CMXRos (M7512) were obtained from Molecular Probes. Bacteria were revealed by immunofluorescence by using in-house polyclonal mouse or rabbit anti-W. chondrophila and anti- $P$. acanthamoebae antibodies. In-house polyclonal antibodies were generated as follows. Rabbits and mice were inoculated four times at day $0,14,28$ and 56 with $500 \mu \mathrm{l}$ PBS containing $5 \times 10^{8}$ heatinactivated $P$. acanthamoebae or $W$. chondrophila cells. Bleedings were obtained before immunization (pre-immune sera) and at day 90.

The secondary antibodies used were Alexa Fluor 488 donkey antirabbit, Alexa Fluor 488 goat anti-mouse, Alexa Fluor 594 goat antimouse and Alexa Fluor 594 goat anti-rabbit (Molecular Probes). Brefeldin A (BFA; Sigma-Aldrich) was used at a final concentration of $10 \mu \mathrm{g} \mathrm{ml}^{-1}$. Macrophages were treated with a final concentration of $20 \mu \mathrm{M}$ nocodazole (Sigma-Aldrich) and/or $10 \mu \mathrm{M}$ cytochalasin D (Sigma-Aldrich), which corresponds to $0.1 \%$ DMSO for a single drug treatment and $0.2 \%$ DMSO for simultaneous treatment with both drugs. Disruption of microtubules and actin filaments with nocodazole and cytochalasin $\mathrm{D}$ was verified by immunostaining of peripheral blood mononuclear cell (PBMC)-derived macrophages with rabbit polyclonal antibodies against alpha-tubulin (ab18251) and mouse monoclonal antibodies against actin (ab11003) obtained from Abcam.

Macrophages. Blood from different healthy volunteers was collected in tubes containing EDTA as an anticoagulant. PBMC were diluted in $0.9 \% \mathrm{NaCl}$ and were separated by centrifugation at $750 \mathrm{~g}$ for $20 \mathrm{~min}$ on Ficoll (Eurobio) and suspended in RPMI-HEPES supplemented with $200 \mathrm{mM}$ L-glutamine (Gibco-BRL Life Technologies) and $10 \%$ fetal calf serum (Gibco-BRL). Next, $10^{5} \mathrm{PBMC} \mathrm{ml}^{-1}$ were incubated for $1 \mathrm{~h}$ at $37^{\circ} \mathrm{C}$ in 24-well cell-culture plates (Corning). Nonadherent cells were removed by washing and the remaining adherent cells were considered to be monocytes, since more than $95 \%$ of these cells expressed CD14 (Capo et al., 1996; Mege et al., 1993). Monocytes were further differentiated into macrophages by incubation at $37{ }^{\circ} \mathrm{C}$ for 7 days in the presence of fetal calf serum.

Infection procedure. The relative bacterial concentration was determined by staining the bacteria with the LIVE/DEAD BacLight bacterial viability kit (Molecular Probes) and was used to estimate the dilution factor to apply to the bacterial culture to infect the macrophages with an m.o.i. between 1 and 10. Macrophages were infected with living or heat-inactivated (for $1 \mathrm{~h}$ at $95{ }^{\circ} \mathrm{C}$ ) bacterial suspension. Plates were centrifuged at $1790 \mathrm{~g}$ for $10 \mathrm{~min}$ at room temperature. After $15 \mathrm{~min}$ of incubation at $37^{\circ} \mathrm{C}$, cells were washed with RPMI-HEPES and further incubated for different periods at $37^{\circ} \mathrm{C}$.

Confocal microscopy. Infected macrophages were washed with PBS and fixed with $4 \%$ paraformaldehyde for 15 min (Lamp-1, v-ATPase, EEA1) or with ice-cold methanol for 4 min (calnexin, PDI, KDEL) or with ice-cold acetone for $10 \mathrm{~min}$ (LysoTracker and MitoTracker). LysoTracker and MitoTracker staining was performed on live cells, before fixation, as described by the manufacturer (Molecular Probes). Cells were then washed three times with PBS and then blocked and permeabilized for $1 \mathrm{~h}$ in a blocking solution (PBS/0.1\% saponin/ $1 \%$ BSA). Saponin $(0.1 \%)$ was included in all subsequent incubation steps except when the LysoTracker probe was used. Coverslips were incubated with primary antibodies directed against different host intracellular markers and bacteria for $1 \mathrm{~h}$ at room temperature in blocking solution or in blocking solution plus $0.1 \%$ saponin for the LysoTracker probe. After washing three times with $\mathrm{PBS} / 0.1 \%$ saponin, coverslips were incubated for $1 \mathrm{~h}$ with secondary antibodies in blocking solution or blocking solution plus $0.1 \%$ saponin for LysoTracker. After three washings in PBS/0.1\% saponin, macrophage and bacteria nucleic acids were stained with DAPI (dilactate, D3571; Molecular Probes). After washing three times with PBS and once with deionized water, the coverslips were mounted onto glass slides using Mowiol (Sigma-Aldrich). Cells were observed on a confocal fluorescence microscope (Zeiss LSM 510 Meta). Files were analysed using Adobe Photoshop and ImageJ for microscopy (http:// www.macbiophotonics.ca) software. To determine the percentage of bacteria that co-localized with the different intracellular markers, a minimum of 100 intracellular bacteria or inclusions were counted. The number of bacteria per macrophage was determined by counting the number of bacteria within about 100 macrophages. All the assays were performed at least in triplicate.

Electron microscopy. Macrophages were infected as described above. Infected cells were harvested at $30 \mathrm{~min}, 3 \mathrm{~h}$ and $8 \mathrm{~h}$ postinfection. After a wash, cells were fixed overnight in $4 \%$ glutaraldehyde and prepared as described previously (Casson et al., 2006). Thin sections on grids were examined with a Philips EM 201 C transmission electron microscope.

Macrophage viability. Cells present on a glass slide were stained for 5-10 min with $0.2 \%$ trypan blue (Sigma-Aldrich). Numbers of living (unstained) and dead (stained) macrophages were determined in triplicate.

Statistical analysis. The mean number of bacteria per macrophage was compared by using the two-tailed unpaired $t$-test (GraphPad Prism version 5.02 for Windows; http://www.graphpad.com). 


\section{RESULTS}

\section{Replication of W. chondrophila in PBMC-derived human macrophages}

In a recent study (Goy et al., 2008), we showed that $W$. chondrophila was able to enter and multiply efficiently within PBMC-derived human macrophages, the mean number of bacteria per infected macrophages increasing by 3 logs in $24 \mathrm{~h}$. A better characterization of bacterial growth during the early events following infection was required in order to understand the association between intracellular trafficking, vacuole biogenesis and bacterial replication. Thus, the number of bacteria per infected macrophage was monitored accurately during the first $8 \mathrm{~h}$ of infection (Fig. 1a). A lag period of about $5 \mathrm{~h}$ was observed, during which bacteria were found within cells but did not replicate. During that time, most EBs differentiated into RBs, with about $40-50 \%$ of bacteria appearing as RBs at $5 \mathrm{~h}$ post-infection. The two stages of development can be easily distinguished by monitoring the size of the bacterial cells and the condensation (EBs) or decondensation (RBs) of the nucleus (not shown). After $5 \mathrm{~h}$, significant bacterial replication occurred, with an increase in the number of bacteria per infected macrophage of about 4 -fold in $3 \mathrm{~h}$, thereby initiating the exponential growth described previously (Goy et al., 2008). At $8 \mathrm{~h}$ post-infection, most bacteria were organized in replicative vacuoles, demonstrated by the presence of a majority of replicating RBs (Fig. 1b). As expected, the number of heat-inactivated $W$. chondrophila cells per infected macrophage remained relatively constant during the first $8 \mathrm{~h}$ of infection, with a minor increase observed between 0 and $2 \mathrm{~h}$ due to ongoing bacterial internalization within macrophages (Goy et al., 2008). As described previously (Greub et al., 2005), the number of $P$. acanthamoebae cells per macrophage increased gradually by about 3 -fold within the first $8 \mathrm{~h}$, albeit with no clear induction of bacterial replication as observed with $W$. chondrophila at $5 \mathrm{~h}$ post-infection.

\section{W. chondrophila evades the endocytic pathway after early endosome compartments}

Considering the important variability in the strategies developed by different intracellular bacteria to resist lysosomal degradation, a broad range of specific markers for intracellular organelles have been used to define the biogenesis of the bacteria-containing vacuoles (BCVs) by immunofluorescence during the course of infection. The studies were performed with live W. chondrophila, and heat-inactivated $W$. chondrophila was used as a control. $P$. acanthamoebae has been used as an additional control since the trafficking of this Chlamydia-like organism has been characterized and the bacteria have been shown to replicate within acidic vacuoles associated with the endocytic pathway (Greub et al., 2005).

We first examined the presence on the BCVs of markers specific for the successive compartments of the endocytic (a)

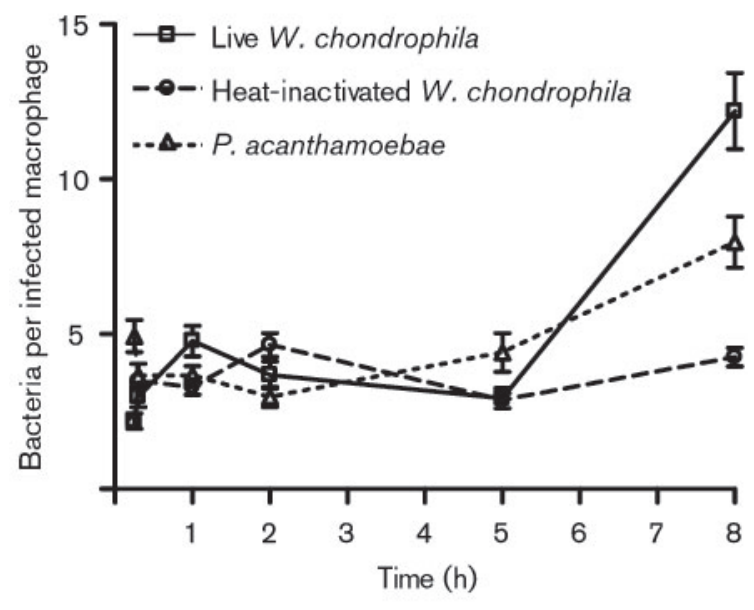

(b)

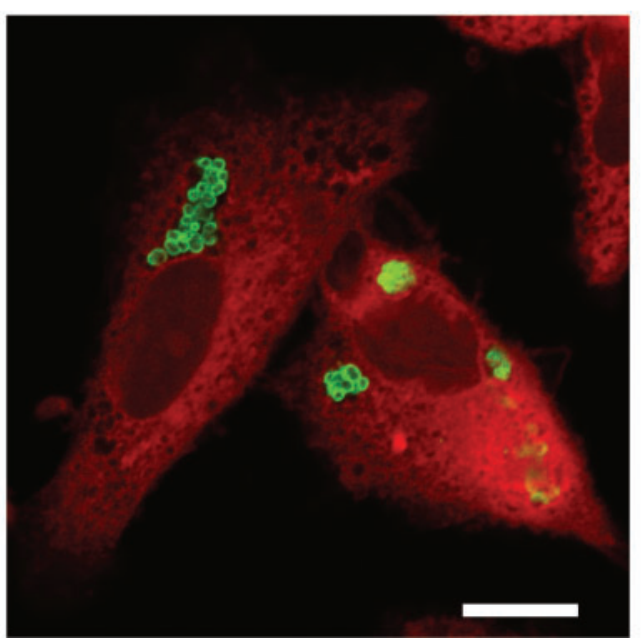

Fig. 1. Bacterial growth within human macrophages. (a) Number of bacteria per infected macrophage during the first $8 \mathrm{~h}$ of infection. Human macrophages were infected with live $W$. chondrophila, heat-inactivated $W$. chondrophila or $P$. acanthamoebae at an m.o.i. of 1-10. Intracellular bacteria were counted at different times post-infection by immunofluorescence. Bacteria and macrophages were labelled as described in (b). The results are means \pm SEM from one of three independent experiments assayed in triplicate. (b) W. chondrophila in human macrophages at $8 \mathrm{~h}$ post-infection. Bacteria (green) were detected by specific mouse anti-W. chondrophila polyclonal antibodies. Macrophages (red) were stained with concanavalin A. Bar, $10 \mu \mathrm{m}$.

pathway. Fifteen minutes after inoculation, W. chondrophila was found in early vacuoles, characterized by the presence of EEA1 (Fig. 2), indicating that early BCVs interact with early endosomes. At 15 min post-infection, about $35 \%$ of the bacteria co-localized with EEA1. This interaction was very transient, since less than $10 \%$ of the BCVs were positive for EEA1 at 60 min post-infection, indicating that EEAl is removed rapidly from BCVs. The dynamics of EEA1 acquisition were similar for vacuoles 
(a)
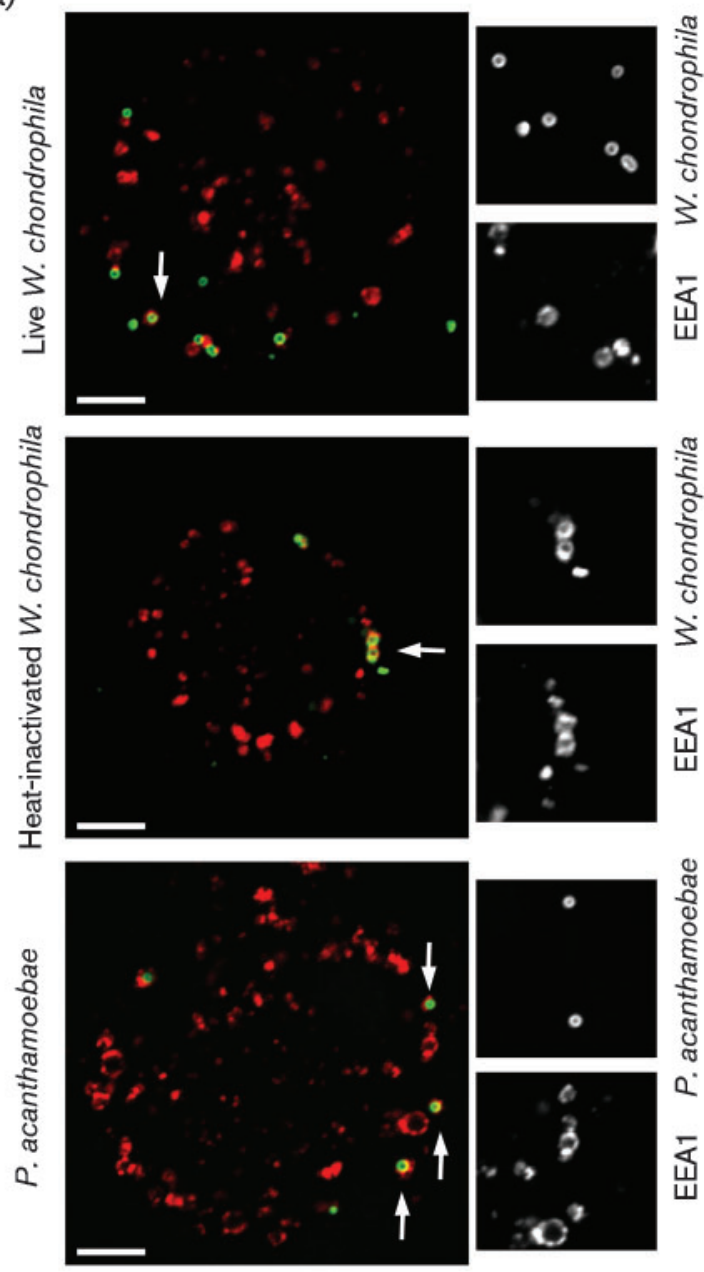

(b)

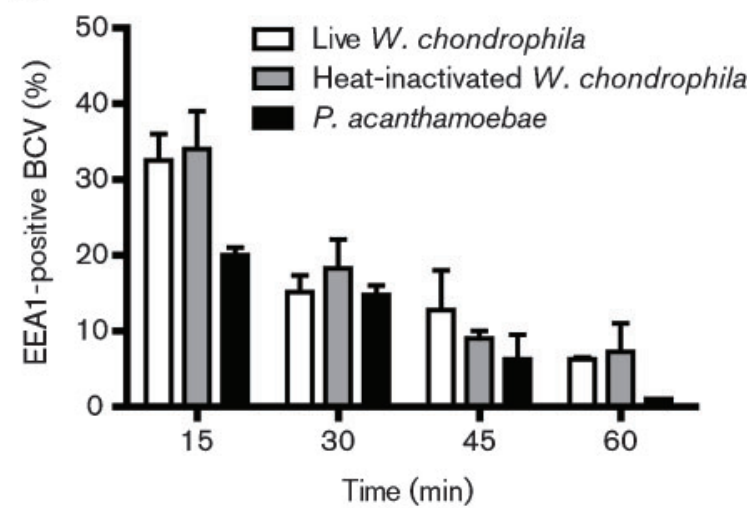

Fig. 2. Transient acquisition of EEA1 by BCVs. (a) Distribution of live $W$. chondrophila, heat-inactivated $W$. chondrophila, live $P$. acanthamoebae and EEA1 at 15 min post-infection. Bacteria (green) and EEA1 (red) were labelled by double indirect immunofluorescence. BCVs that co-localize with EEA1 are indicated by white arrows and are magnified in the right panels. Bars, $5 \mu \mathrm{m}$. (b) Percentage of BCVs that were decorated with EEA1 at various times post-infection. Data represent means $\pm S D$ from three independent experiments performed in duplicate. containing live $W$. chondrophila, heat-inactivated $W$. chondrophila and P. acanthamoebae, implying that internalization and the early events of biogenesis appear to be similar between the live $W$. chondrophila and the controls.

We next examined the presence of the lysosomal-associated membrane protein 1 (Lamp-1) and of the vacuolar proton pump v-ATPase, two late endosome-lysosome markers (Fig. 3). In contrast to the vacuoles containing heatinactivated $W$. chondrophila and live $P$. acanthamoebae, the live $W$. chondrophila vacuoles never co-localized with Lamp-1 and v-ATPase. At $4 \mathrm{~h}$ post-infection, $70-80 \%$ of heat-inactivated $W$. chondrophila and $P$. acanthamoebae BCVs were labelled with Lamp-1 and remained positive. The acquisition of v-ATPase was similar to Lamp- 1 for the heat-inactivated $W$. chondrophila, with more than $80 \%$ of the BCVs positive at $4 \mathrm{~h}$. As demonstrated previously (Greub et al., 2005), P. acanthamoebae acquired the vATPase transiently, with a maximum of co-localization of about $54 \%$ at $4 \mathrm{~h}$ post-infection. In contrast, most of the vacuoles containing the live $W$. chondrophila excluded both Lamp-1 and v-ATPase. Indeed, during the first $8 \mathrm{~h}$ of infection, these late endosome-lysosome markers were detected in less than $15 \%$ of the live W. chondrophila $\mathrm{BCV}$ s, indicating that vacuoles containing live $W$. chondrophila did not acquire late endosome-lysosome traits. The delivery of proton pump v-ATPase to the phagosome is involved in rapid acidification of the lumen of these vesicles that characterize late-endosomal/lysosomal compartments (Bellaire et al., 2005). The LysoTracker Red probe is a fluorescent acidotropic probe used to monitor acidic organelles in cells and is therefore a direct probe for phagosome acidification in macrophages (Bandyopadhyay et al., 2007; Via et al., 1998). Most of the heat-inactivated W. chondrophila and P. acanthamoebae co-localized with the acidic probe at $8 \mathrm{~h}$ post-infection, whereas the live $W$. chondrophila BCVs remained mainly negative for LysoTracker Red (Fig. 4), implying that the live $W$. chondrophila replicative vacuole was not acidic. Taken together, these results demonstrate that live W. chondrophila interact with early but not late compartments of the endocytic pathway in PBMC-derived human macrophages, indicating that the bacteria evade the endocytic pathway rapidly after internalization.

\section{W. chondrophila recruits mitochondria to its replicative vacuole in human macrophages}

As live W. chondrophila appear to bypass the late endocytic pathway and to lose early endosome compartment markers rapidly after phagocytosis, we analysed the association of the BCVs with other compartments of human macrophages. It has been reported previously that vacuoles containing $W$. chondrophila were surrounded by host-cell mitochondria in both BT cells (ATCC CRL 1390), the host cell of the original isolation of the bacterium from an aborted bovine fetus, and P388D1 mouse macrophage cells (ATCC TIB 63) (Kocan et al., 1990). We therefore first 
(a)
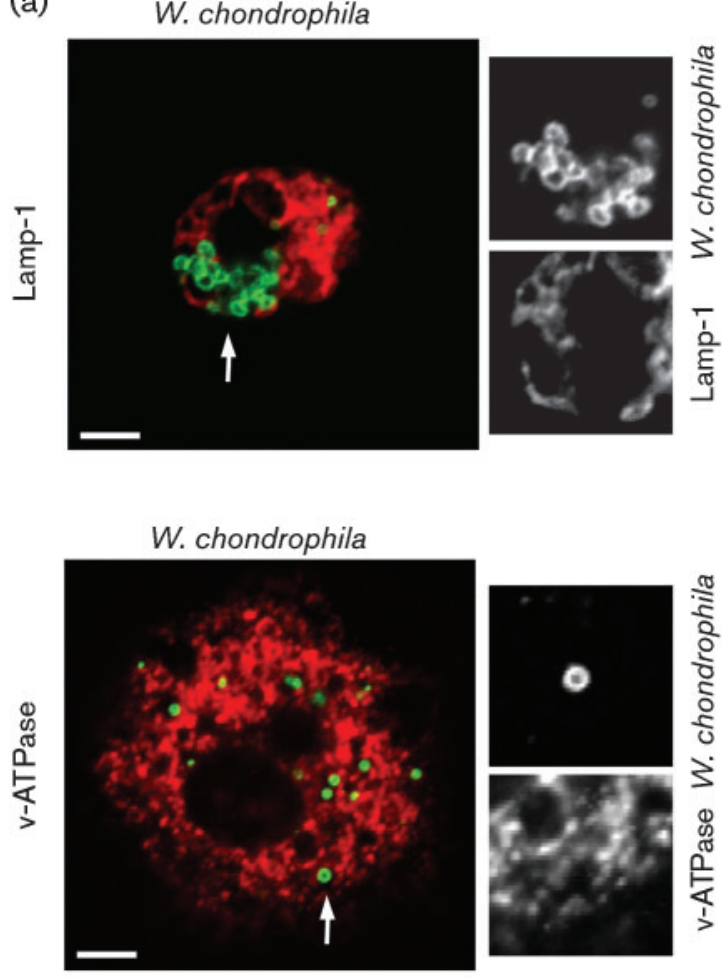
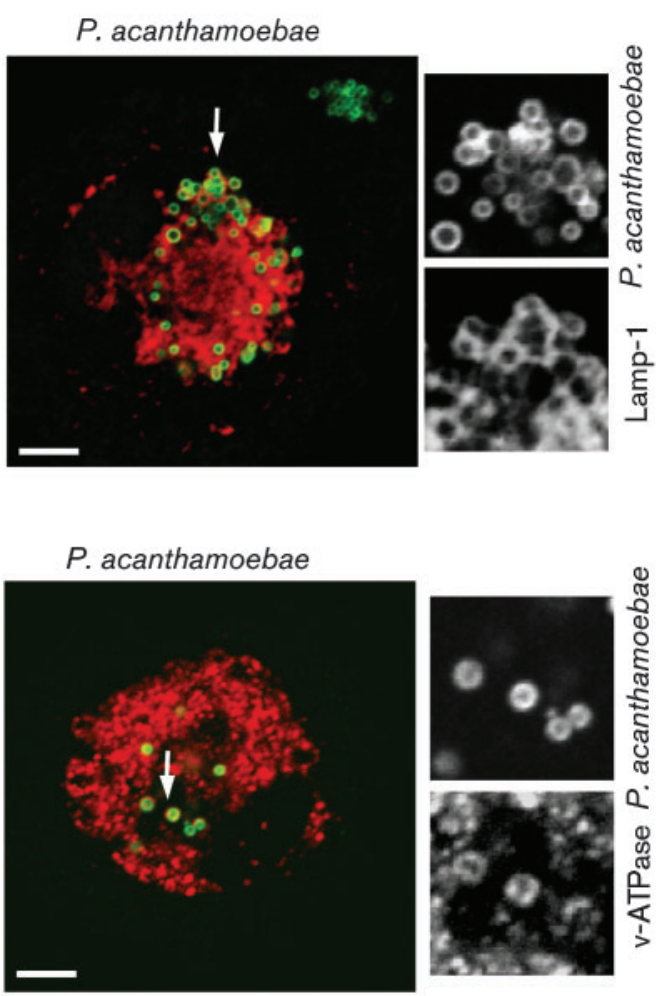

(b)
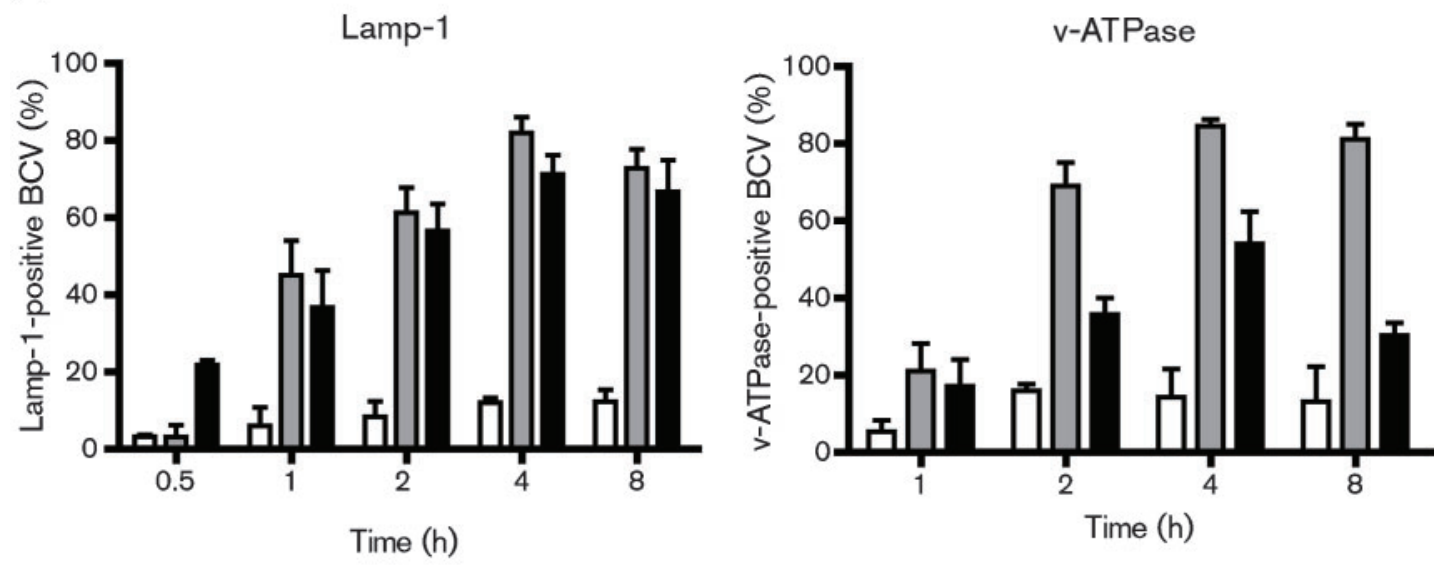

Live W. chondrophila

Heat-inactivated W. chondrophila

$P$. acanthamoebae

Fig. 3. W. chondrophila rapidly evades the endocytic pathway and $W$. chondrophila BCVs do not associate with late endosome and lysosome markers. (a) P. acanthamoebae but not W. chondrophila is trafficked within BCVs associated with the endocytic pathway, since only $P$. acanthamoebae-containing vacuoles co-localize with the late endosome/lysosome markers Lamp-1 and v-ATPase. Bacteria (green) and organelle markers (red) were fixed and detected by double immunofluorescence at $8 \mathrm{~h}$ post-infection. Bacteria and the surrounding area, indicated by white arrows, are magnified in the right panels. Bars, $5 \mu \mathrm{m}$. (b) Percentage of BCVs associated with the organelle markers Lamp-1 and v-ATPase at various times post-infection. Data represent means $\pm S D$ from three independent experiments assayed in duplicate.

investigated mitochondrial recruitment to BCVs in human macrophages with the MitoTracker Red probe, which selectively stains mitochondria in both live and fixed cells.
Host-cell mitochondria were recruited rapidly and gradually to live $W$. chondrophila compartments, since about $50 \%$ of the live $W$. chondrophila-containing vacuoles were 

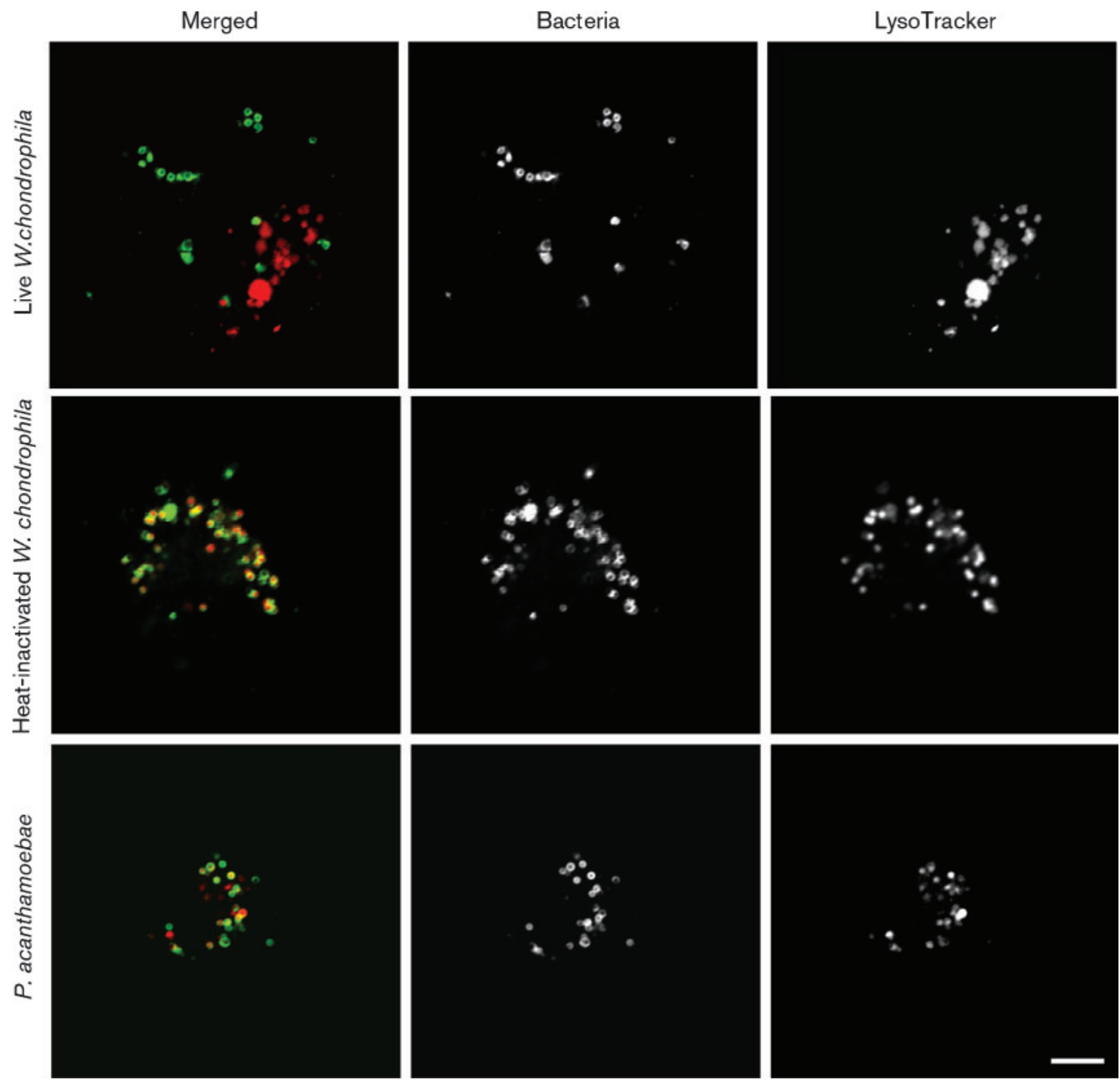

Fig. 4. $W$. chondrophila-containing vacuoles are not acidified during human macrophage infection. At $8 \mathrm{~h}$ post-infection, in contrast to $W$. chondrophila, heat-inactivated $W$. chondrophila and $P$. acanthamoebae BCVs accumulated the fluorescent acidotropic probe LysoTracker Red used to monitor acidic phagosomes in macrophages. Bacteria (green) and LysoTracker (red) were detected by immunofluorescence and direct labelling, respectively. Bar, $5 \mu \mathrm{m}$.

decorated with mitochondria at $2 \mathrm{~h}$ post-infection and more than $80 \%$ at $8 \mathrm{~h}$ post-infection (Fig. 5). Electron microscopy showed that mitochondria were found in intimate association with live $W$. chondrophila BCVs (Fig. 6). The contact between the outer mitochondrial membrane and the BCV membrane was continuous over the entire length of the mitochondrial profile, and the majority of the $W$. chondrophila inclusion membrane surface area was associated with mitochondria (Fig. 6b). Moreover, electron microscopy revealed that some $W$. chondrophila BCVs recruited mitochondria as early as 30 min post-infection, indicating that the recruitment of mitochondria started rapidly after phagocytosis (not shown). Both heat-inactivated $W$. chondrophila and $P$. acanthamoebae remained negative for host-cell mitochondrion recruitment, with less than $6 \%$ of the vacuoles containing heat-inactivated $W$. chondrophila and $3 \%$ of those containing $P$. acanthamoebae being poorly associated with mitochondria at $8 \mathrm{~h}$ post-infection.

These results indicate that $W$. chondrophila BCVs rapidly and gradually recruited mitochondria to bacterial vacuoles quickly after evasion from the endocytic pathway to form an intimate association with this organelle.

\section{W. chondrophila BCVs co-localize with ER markers during maturation into a replicative organelle}

To characterize $W$. chondrophila intracellular trafficking and vacuole maturation further, a triple immunofluorescence labelling was performed with markers specific for the 

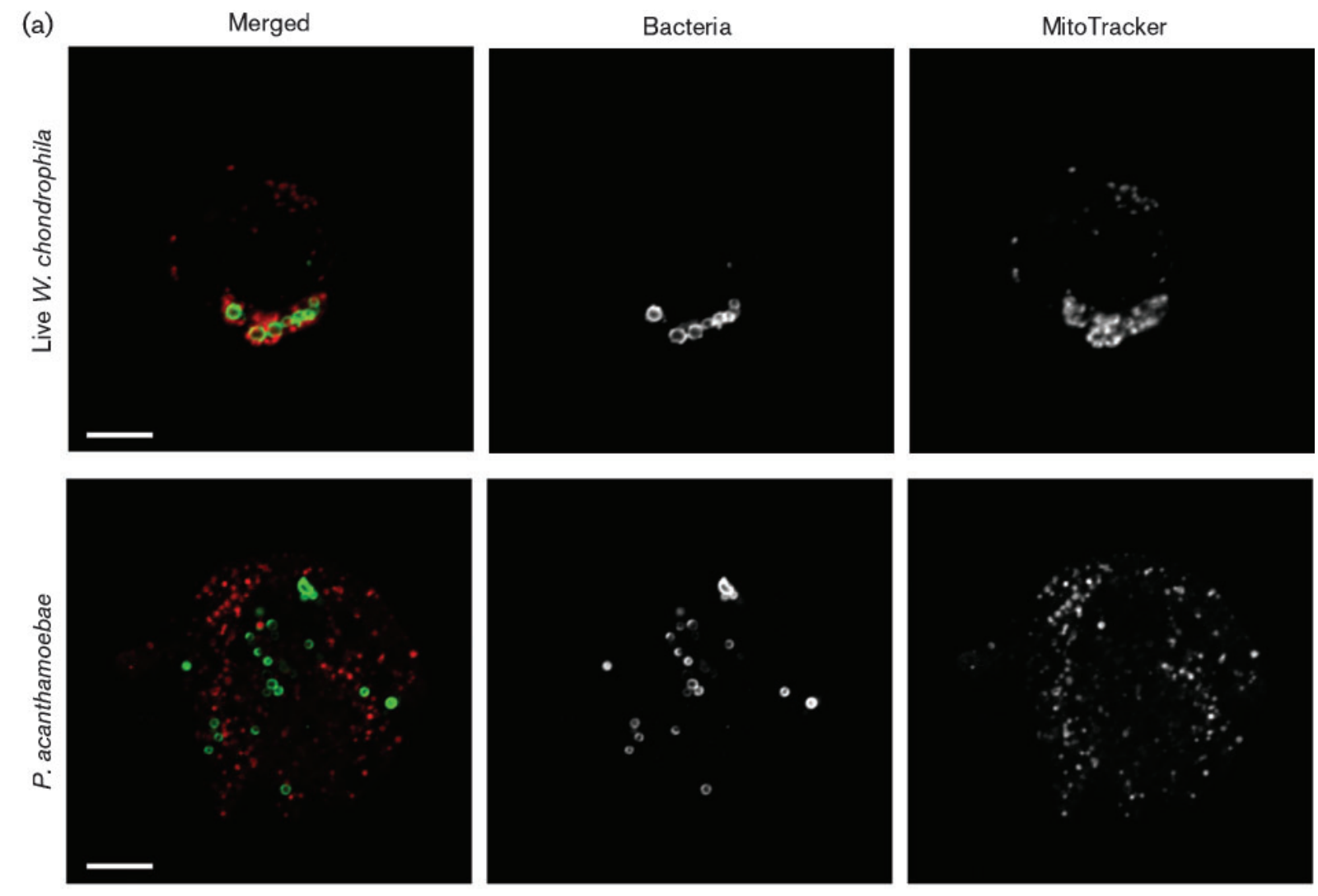

(b)

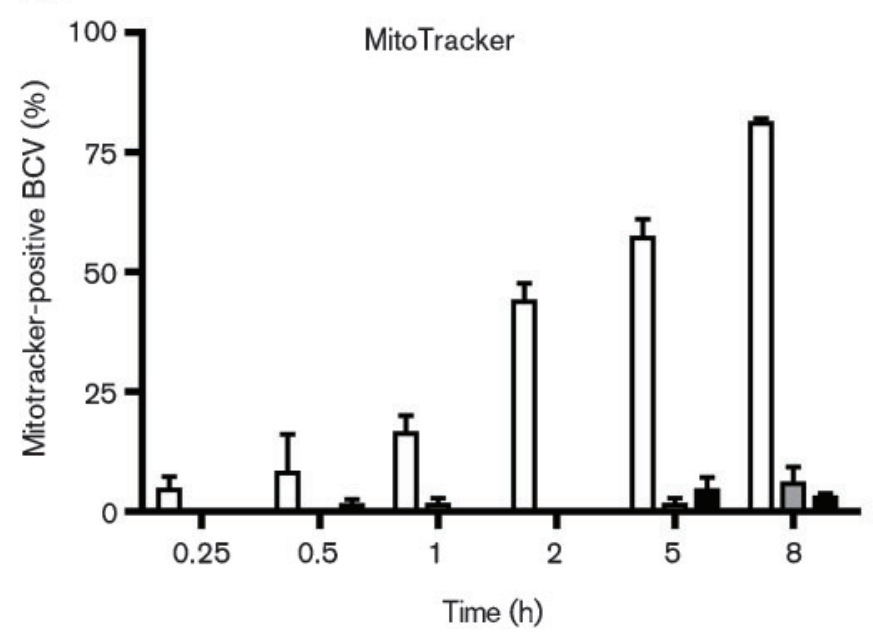

Live W. chondrophila

Heat-inactivated W. chondrophila

P. acanthamoebae

Fig. 5. Intracellular trafficking of $W$. chondrophila in human macrophages showing the association of BCVs with mitochondria. (a) W. chondrophila inclusions are associated with mitochondria, as shown by co-localization of MitoTracker CMXRos with W. chondrophila BCVs at $8 \mathrm{~h}$ post-infection, whereas $P$. acanthamoebae was unable to recruit mitochondria to its replicative organelle. Bacteria (green) and MitoTracker (red) were detected by immunofluorescence and direct labelling. Bars, $5 \mu \mathrm{m}$. (b) Percentage of bacteria enclosed in vacuoles positive for MitoTracker at various times post-infection. Data represent means \pm SD from three independent experiments assayed in duplicate.

ER (calnexin) and the Golgi apparatus (GM130) and with the counterstain DAPI, which labelled both bacterial DNA and the nucleus of human macrophages. At the time of replication, $8 \mathrm{~h}$ post-infection, a significant co-localization of the ER marker calnexin was observed with the live $W$. chondrophila but not with the control $P$. acanthamoebae 
(a)

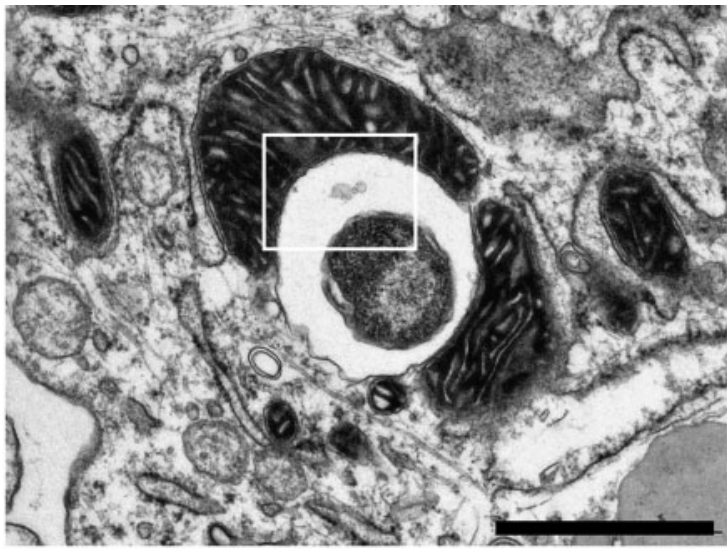

(c)

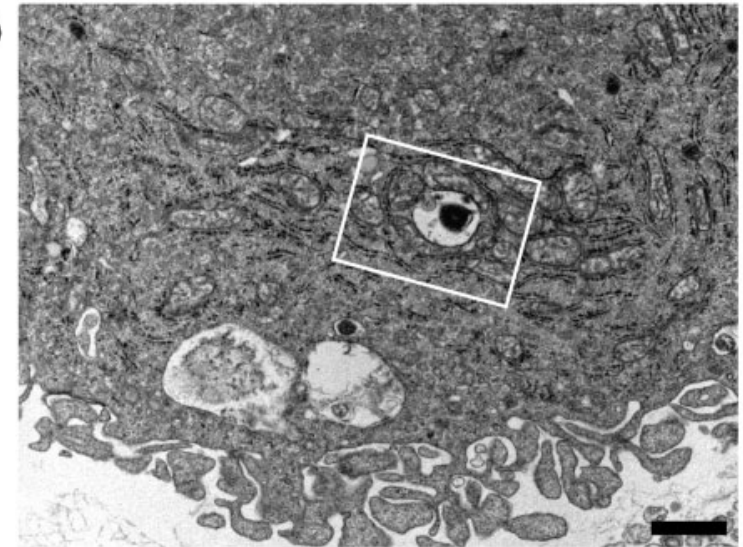

(e)

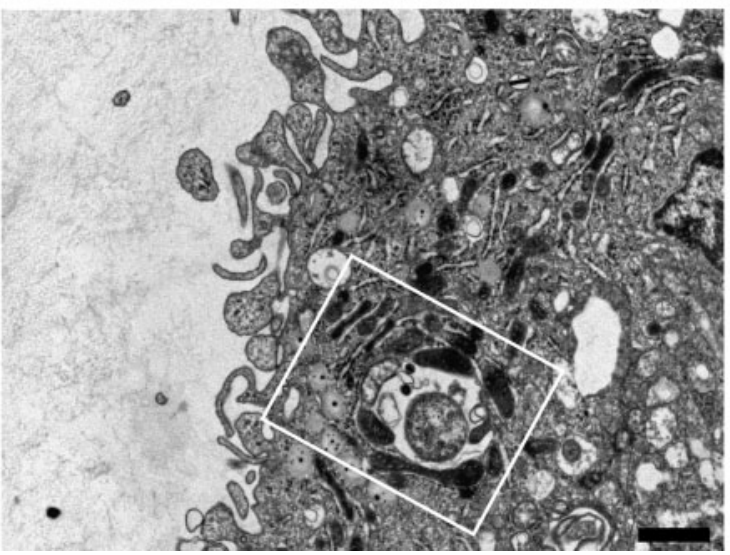

(b)

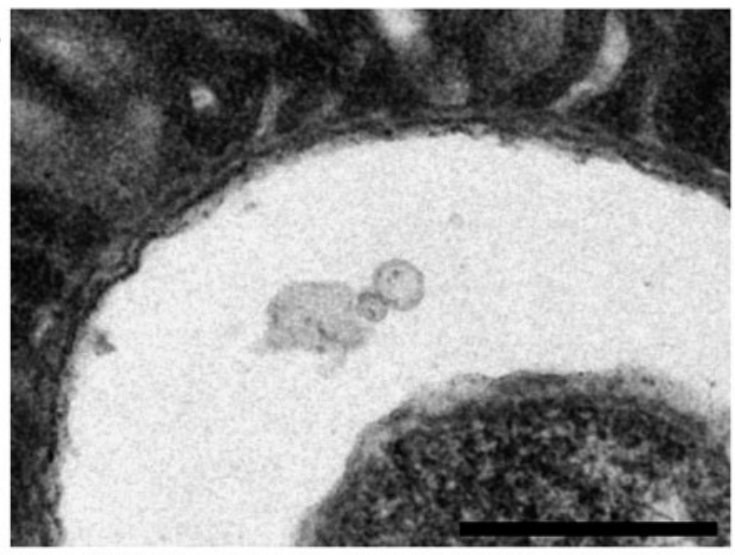

(d)

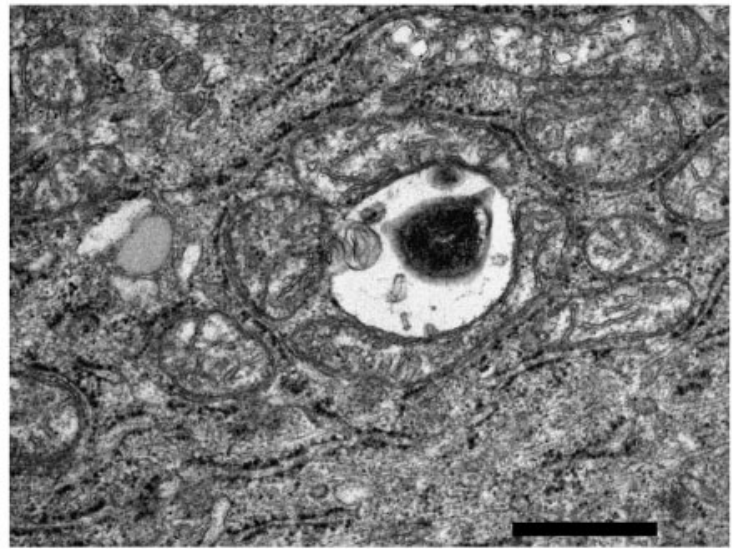

$(f)$

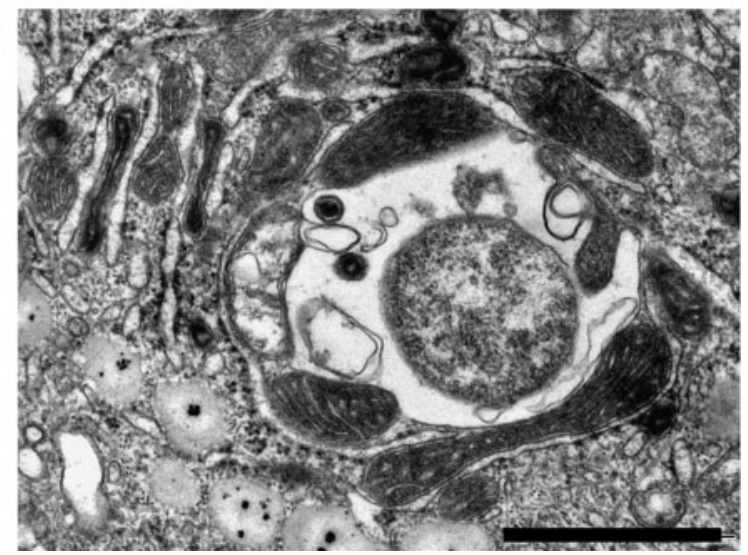

Fig. 6. Electron micrographs of $W$. chondrophila-containing vacuoles associated with mitochondria and the $E R$ at various times post-infection. (a) At $3 \mathrm{~h}$ post-infection, about $50 \%$ of the $W$. chondrophila-containing vacuole membranes are tightly associated with mitochondria. Bar, $1 \mu \mathrm{m}$. (b) Enlargement of (a) showing that the contact between the membrane of the BCV and the outer membrane of the mitochondrion is continuous over the entire length of the association. Bar, $0.25 \mu \mathrm{m}$. (c) At $3 \mathrm{~h}$ post-infection, between 20 and $30 \%$ of $W$. chondrophila BCVs closely associated with mitochondria are localized in ER-rich areas. (d) Enlargement of the inclusion in (c) showing a network of ER surrounding the $W$. chondrophila inclusion intimately associated with mitochondria. Bar, $1 \mu \mathrm{m}$. (e) Most of the W. chondrophila inclusions are located in ER-rich areas within human macrophages at $8 \mathrm{~h}$ post-infection. Bar, $1 \mu \mathrm{m}$. (f) Enlargement of the $W$. chondrophila BCV depicted in (e) showing that mitochondria and ER associated with $W$. chondrophila-containing vacuoles form an interlaced and interconnected organelle network around the bacterial inclusions. Significant membrane continuities between mitochondria and ER can be observed. The membrane connections between ER and mitochondria or the BCV membrane are devoid of ribosomes at the interacting faces. Bar, $1 \mu \mathrm{m}$. 

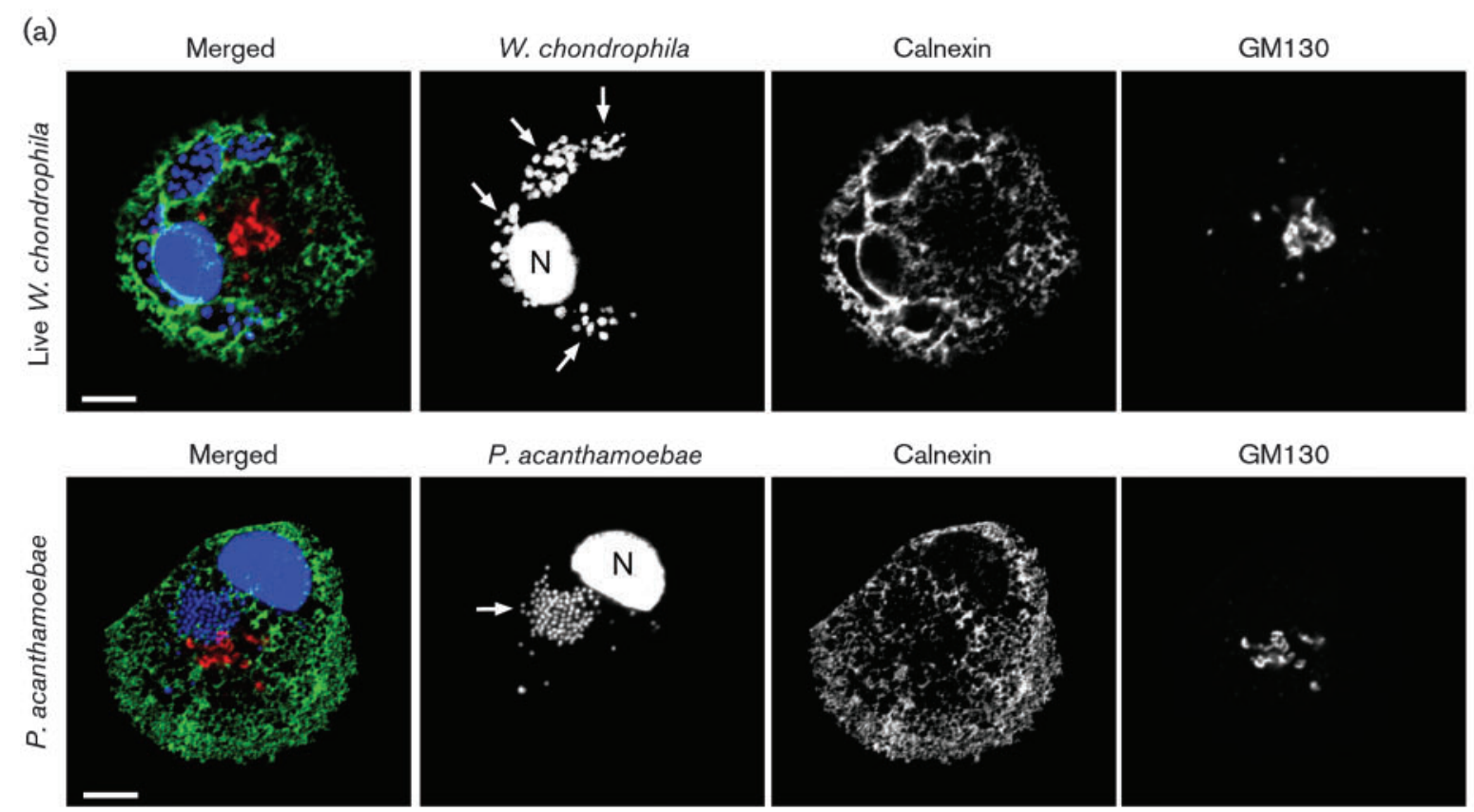

P. acanthamoebae

Calnexin

GM130
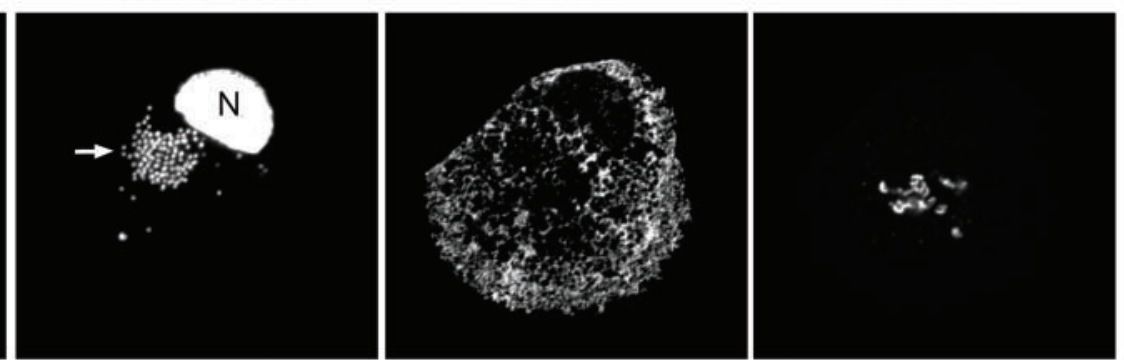

$2 \mathrm{~h}$

$4 \mathrm{~h}$

$8 \mathrm{~h}$

(b)
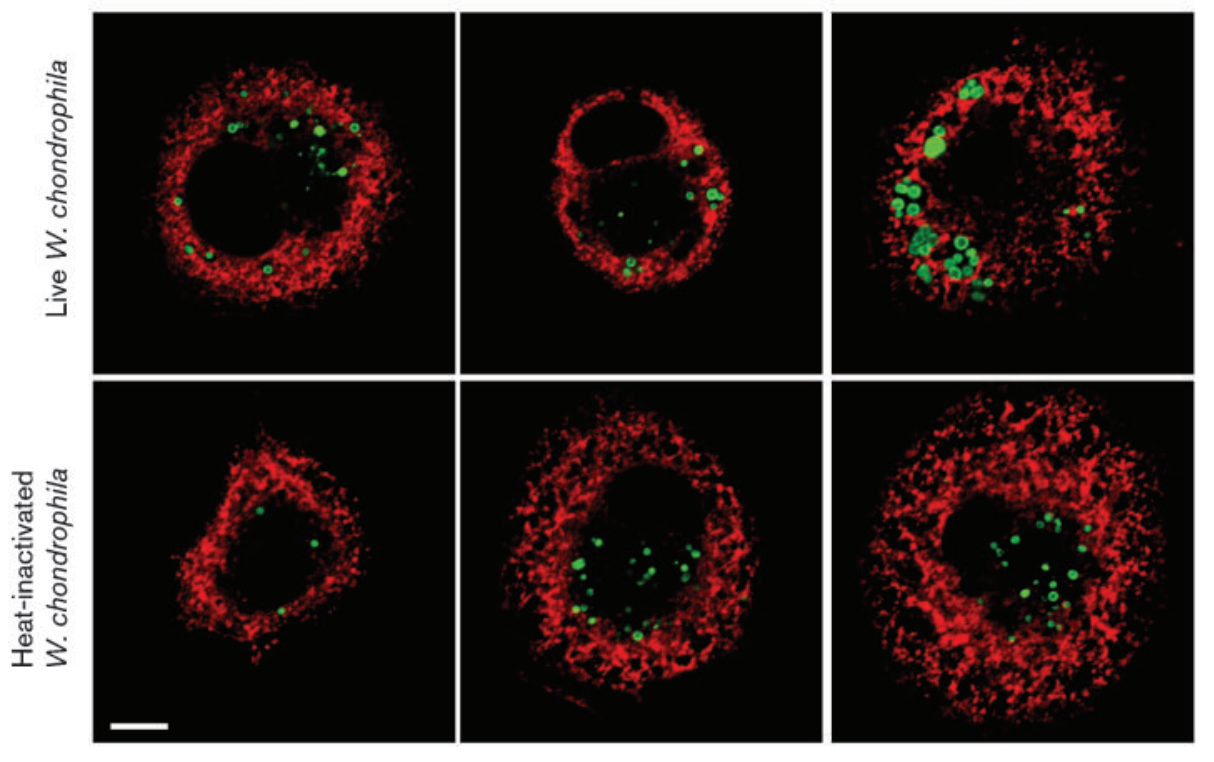

(c)
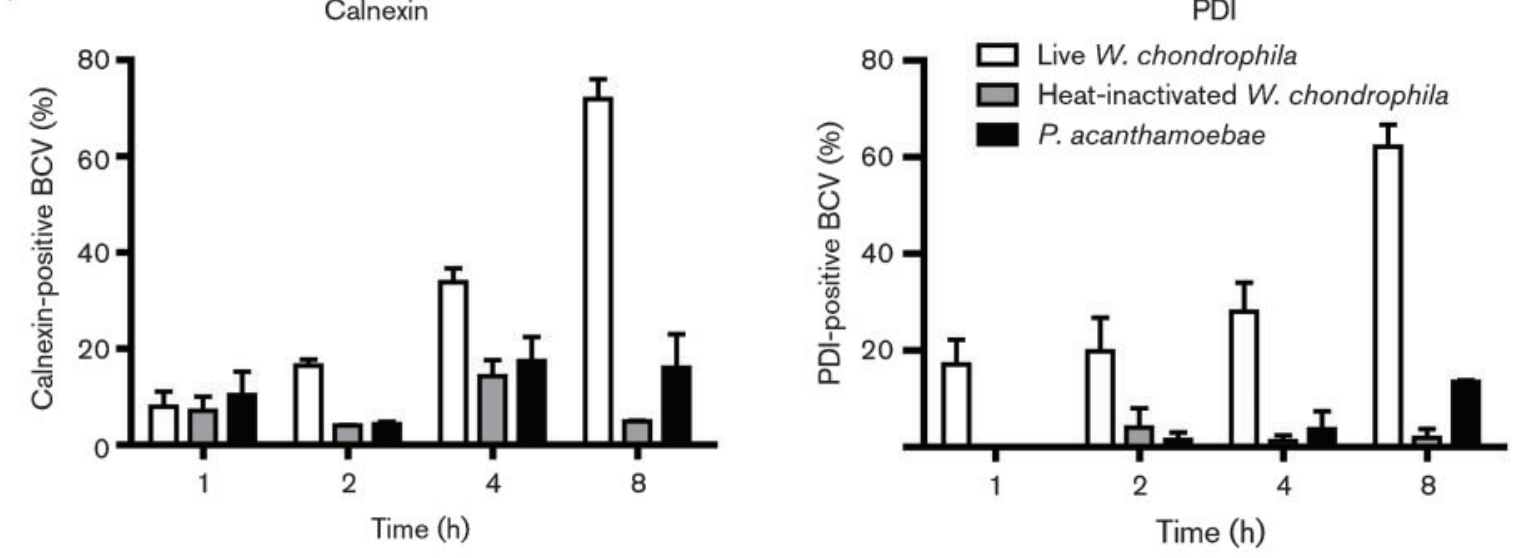
Fig. 7. Intracellular trafficking of $W$. chondrophila in human macrophages is characterized by a co-localization of the BCVs with the ER. (a) Intracellular trafficking demonstrated by triple immunofluorescence labelling with calnexin (ER; green), GM130 (Golgi; red) and the counterstain DAPI (bacteria and nuclei of macrophages; blue). W. chondrophila but not $P$. acanthamoebae inclusions are associated with the ER, as shown by co-localization of calnexin with $W$. chondrophila-containing vacuoles at $8 \mathrm{~h}$ post-infection. Arrows indicate bacterial inclusions. N, Nucleus. Bar, $5 \mu \mathrm{m}$. (b) Co-localization of live and heat-inactivated $W$. chondrophila-containing vacuoles with the ER marker PDI at 2, 4 and $8 \mathrm{~h}$ post-infection. The live W. chondrophila BCVs gradually co-localize with the ER during human macrophage infections, whereas no association is observed with the heatinactivated bacteria, which are directed to a macrophage compartment enriched in late endosomes and lysosomes. At $8 \mathrm{~h}$ postinfection, the majority of BCVs characterized by replicating bacteria co-localize with the ER. Bar, $5 \mu \mathrm{m}$. (c) W. chondrophila colocalizes with the ER markers calnexin and PDI. Percentages of bacteria enclosed in vacuoles that positively co-localize with calnexin or PDI are shown at various times post-infection. The co-localization of BCVs with calnexin or PDI was considered positive when a clear co-localization with dense ER regions was observed, as shown in (a) and (b), and negative when no colocalization or co-localization with sparse ER was observed, as shown in (b) for heat-inactivated W. chondrophila and in (a) for $P$. acanthamoebae, respectively. Data represent means \pm SD from three independent experiments assayed in duplicate.

BCVs (Fig. 7a). At the same time, the bacteria clearly did not co-localize with the Golgi marker GM130. We further monitored the presence of ER markers such as calnexin, $\mathrm{PDI}$ and KDEL in close association with BCVs during the course of infection (Fig. 7b, c). In most PBMC-derived human macrophages, the ER is largely not distributed everywhere in the cell but in distinct zones, mainly localized around the nucleus and at the periphery of the cell. Furthermore, dense and sparse ER regions can be easily distinguished. The co-localization of BCVs with calnexin or PDI was considered positive when a clear co-localization with dense ER regions was observed, as shown in Fig. $7(\mathrm{a}, \mathrm{b})$, and negative when no colocalization or co-localization with sparse ER was observed, as shown in Fig. 7(b) for heat-inactivated W. chondrophila and in Fig. 7(a) for P. acanthamoebae, respectively. The live $W$. chondrophila-containing vacuoles co-localized gradually and at the same rate with calnexin and PDI, with respectively 34 and $28 \%$ of the BCVs positive for these ER markers at $4 \mathrm{~h}$ post-infection. The proportion of live $W$. chondrophila BCVs that localized within dense calnexin and PDI regions increased greatly between 4 and $8 \mathrm{~h}$, to reach 72 and $62 \%$ co-localization, respectively, at $8 \mathrm{~h}$ post-infection. Similar results were obtained with KDEL (not shown). This period corresponds precisely to the transition of $W$. chondrophila from a non-replicating state into a replication-competent state, demonstrated previously by the induction of replication at $5 \mathrm{~h}$ post-infection (Fig. 1). In contrast, heat-inactivated $W$. chondrophila and P. acanthamoebae did not show significant co-localization with ER markers, with no more than 14.3 and $17.4 \%$ of calnexin-positive BCVs and 1.9 and $13.5 \%$ of PDI-positive BCVs, respectively.

The localization of $W$. chondrophila-containing vacuoles within dense ER regions was also observed by electron microscopy (Fig. 6). However, in contrast to mitochondria, no apparent close association between the bacterial vacuole and the ER membranes was observed. The W. chondrophila inclusion seemed to be surrounded by two layers of interconnected organelles, with an inner layer composed mostly of mitochondria that form a tight and continuous association with the BCV membrane and an outer layer composed mainly of ER interlaced with mitochondria, with rare stretches of ER in direct contact with the bacterial vacuole membrane. Interestingly, significant membrane continuity between the ER and mitochondria associated with BCVs was observed. Moreover, stretches of interaction between mitochondria and ER were devoid of ribosomes at the interacting faces.

Throughout the course of infection of human macrophages, the great majority of live $W$. chondrophila-containing vacuoles trafficked to areas of intense ER immunofluorescence staining. Moreover, the co-localization of ER with BCVs apparently occurred after recruitment of mitochondria, indicating that a sequential development process, characterized first by an association of the $W$. chondrophila-containing compartment with mitochondria and secondly by co-localization with ER, occurs after evasion of the phagocytic pathway (Figs 5 and 7). Finally, the association of W. chondrophila BCVs with mitochondria in dense ER regions may be required in order to form a mature vacuole that supports intracellular replication.

\section{Biogenesis of the $W$. chondrophila replicative vacuole requires ER-Golgi COPI-dependent vesicular transport}

The intracellular pathogens Legionella pneumophila and Brucella abortus replicate within macrophages in ERderived organelles (Celli et al., 2003; Duclos \& Desjardins, 2000; Roy \& Tilney, 2002). The biogenesis of the L. pneumophila but not of the B. abortus replicative organelle requires ER-Golgi COPI-dependent vesicular transport, since L. pneumophila intracellular replication can be inhibited when macrophages are treated with BFA. To examine whether $W$. chondrophila replication is affected by the inhibition of ER-Golgi COPI-dependent vesicular transport, PBMC-derived human macrophages were treated with BFA prior to or at various times during infection. Macrophage viability was determined by trypan blue exclusion assay, which detected no differences in 
viability between BFA-treated and untreated macrophages. Intracellular growth of $W$. chondrophila was inhibited significantly when macrophages were treated with BFA from 0 to $8 \mathrm{~h}$ and also from 2.5 to $5.5 \mathrm{~h}$ during infection $(P<0.0001)$ (Fig. 8a). The growth of $W$. chondrophila was inhibited poorly when macrophages were treated with BFA from 5 to $8 \mathrm{~h}(P=0.043)$. There was no effect on bacterial growth when macrophages were treated with BFA from 0 to $3 \mathrm{~h}$ during infection. Moreover, W. chondrophila growth and internalization were not inhibited when macrophages were pretreated with BFA $30 \mathrm{~min}$ before infection and subsequently for $3 \mathrm{~h}$ (not shown), indicating that bacterial internalization was not affected by BFA. To analyse the replication potential of $W$. chondrophila further under the different BFA treatment conditions, the number of bacteria per replicative vacuole was counted (not shown). Replicative organelles contained significantly fewer bacteria in macrophages that were treated with BFA from 0 to $8 \mathrm{~h}(P<0.0001)$ and from 2.5 to $5.5 \mathrm{~h}$ $(P=0.0044)$, whereas no differences were seen between the untreated control and the other incubation times tested. In addition, the growth of $P$. acanthamoebae was not affected significantly $(P>0.05)$ by BFA treatments, demonstrating that BFA specifically inhibits the growth of $W$. chondrophila (Fig. 8a). These results demonstrate that ER-Golgi COPI-dependent vesicular transport inhibited by BFA is essential during a short period, between 2.5 and $5.5 \mathrm{~h}$ post-infection, of the biogenesis of the $W$. chondrophila replicative organelle. Treatment of macrophages with BFA before or after that period had no apparent effect on the rate of bacterial multiplication.

\section{Mitochondria are recruited to BCVs via microtubules and/or actin microfilaments in human macrophages}

Mitochondrial movement, distribution and anchorage depend on both actin microfilaments and microtubules (Boldogh \& Pon, 2006; Frederick \& Shaw, 2007; Ligon \& Steward, 2000; Morris \& Hollenbeck, 1995). To characterize mitochondrial recruitment to $W$. chondrophila BCVs further, PBMC-derived macrophages were treated with the microtubule-depolymerizing agent nocodazole at various times during infection. Microtubule disruption by treatment with nocodazole from 0 to $8 \mathrm{~h}$ showed only a minor alteration of mitochondrial recruitment to BCVs and of bacterial growth (Fig. 8b). These data indicate that an alternative mechanism to mitochondrial recruitment along microtubules is used by $W$. chondrophila in human macrophages. To test whether the bacteria have developed an alternative pathway via actin microfilaments to recruit mitochondria to the inclusion membrane, macrophages treated with the actin microfilament-depolymerizing agent cytochalasin D were infected with $W$. chondrophila. Only a minor reduction of mitochondrial recruitment to BCVs and no significant decrease in bacterial growth were observed when macrophages were treated from 0 to $8 \mathrm{~h}$ with cytochalasin D. Considering that mitochondria can move along both microtubules and actin microfilaments, disruption of these two cytoskeleton elements may be required in order to block mitochondrial recruitment to $W$. chondrophila inclusions efficiently. Indeed, mitochondrial recruitment to BCVs and bacterial growth were abolished almost completely when both microtubules and actin microfilaments were depolymerized by simultaneous nocodazole and cytochalasin D treatments (Fig. 8b). Mitochondrial recruitment ceased and the number of bacteria per macrophage decreased significantly at $8 \mathrm{~h}$ post-infection when macrophages were treated with nocodazole and cytochalasin $\mathrm{D}$ at 3 and $5 \mathrm{~h}$ postinfection, respectively. Moreover, the percentages of MitoTracker-positive BCVs observed when macrophages were treated with nocodazole and cytochalasin D at 3 and $5 \mathrm{~h}$ post-infection are consistent with the kinetics of mitochondrial recruitment observed at these time points, as shown in Fig. 5. This indicates that mitochondrial recruitment is blocked rapidly upon simultaneous microtubule and actin filament disruption. Mitochondrial recruitment and bacterial growth were recovered when nocodazole and cytochalasin D were washed away at 3 and $5 \mathrm{~h}$ post-infection, respectively, suggesting that the bacteria are able to survive the treatment and to induce the maturation process efficiently as soon as an intact cytoskeleton is formed in host macrophages. Indeed, the growth observed at $8 \mathrm{~h}$ when nocodazole and cytochalasin $\mathrm{D}$ were removed at $3 \mathrm{~h}(0-3 \mathrm{~h})$ and $5 \mathrm{~h}(0-5 \mathrm{~h})$ postinfection corresponds to the bacterial growth observed when macrophages were treated at 5-8 h and 3-8 h postincubation, respectively.

Knowing that bacterial entry could be an issue following nocodazole and cytochalasin D treatment, several incubation times after most bacterial internalization had occurred during bacterial infection were tested, that is $2 \mathrm{~h}$ post-infection, as shown previously (Fig. 1a). As shown in Fig. 8(b), treatment with nocodazole and cytochalasin D at $3 \mathrm{~h}$ post-infection inhibited both mitochondrial recruitment and bacterial growth significantly. In addition, simultaneous drug treatment of macrophages between 0 and $3 \mathrm{~h}$ showed only minor decreases in both mitochondrial recruitment and bacterial growth. These data strongly suggest that the inhibition of bacterial development and thus bacterial growth by nocodazole plus cytochalasin $\mathrm{D}$ is probably not caused by inhibition of bacterial entry.

These results indicate that separate disruption of microtubules or actin filaments has only a minor effect on mitochondrial recruitment to BCVs and on bacterial growth. However, mitochondrial recruitment to $W$. chondrophila inclusions and bacterial growth are strongly impaired when both cytoskeletal systems are disrupted simultaneously. These data suggest that the bacterium has evolved multiple mechanisms to recruit to its $\mathrm{BCV}$ an organelle required for its maturation process. 
(a)

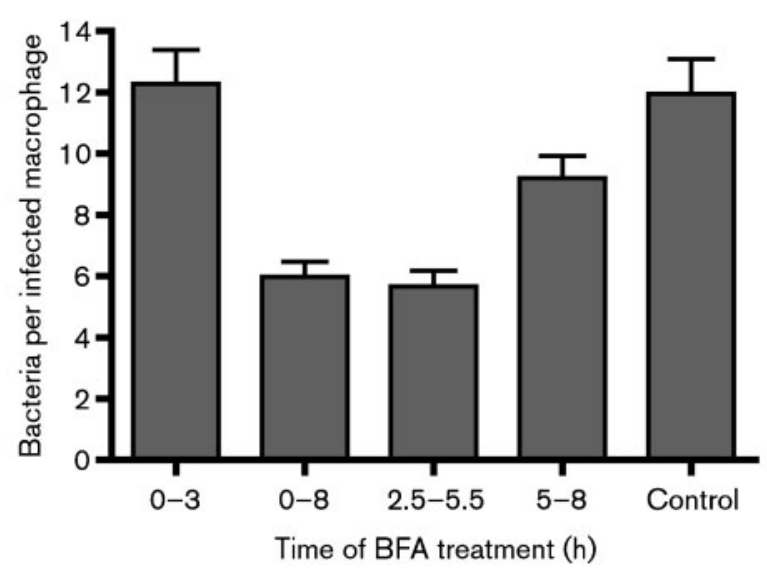

(b)

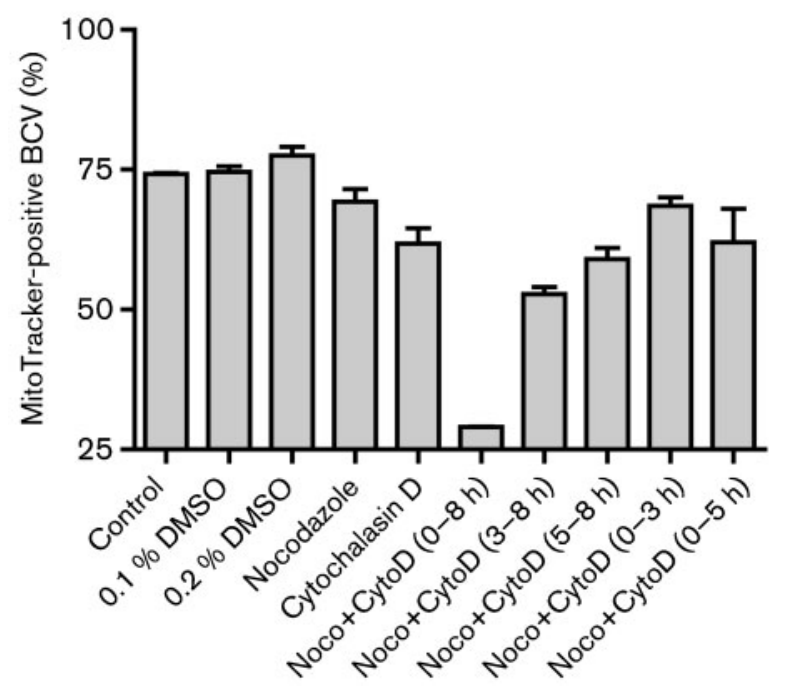

P. acanthamoebae
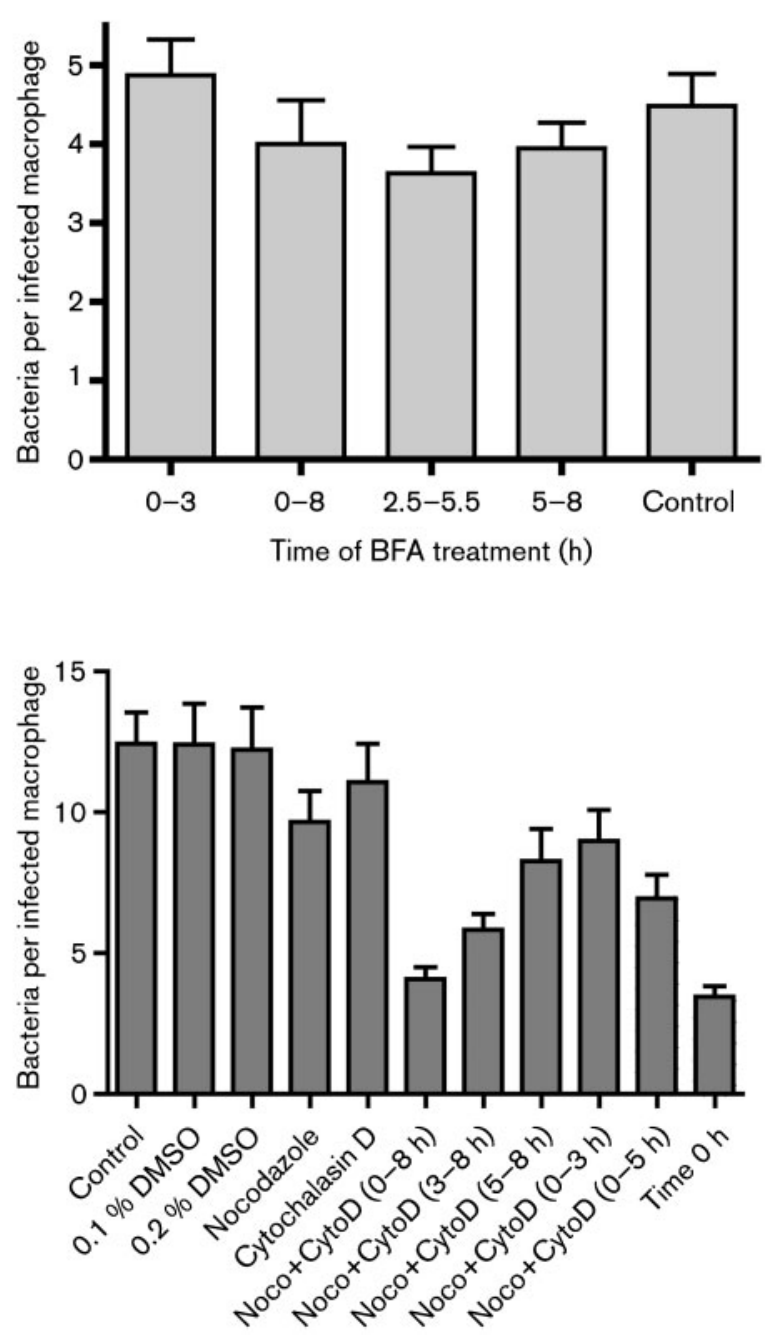

Fig. 8. W. chondrophila intracellular replication is inhibited by BFA and by simultaneous treatment with nocodazole and cytochalasin D. (a) W. chondrophila intracellular replication requires ER-Golgi COPI-dependent vesicular transport that can be inhibited by BFA. Human macrophages infected with $W$. chondrophila and $P$. acanthamoebae were treated with $10 \mu \mathrm{g}$ BFA $\mathrm{ml}^{-1}$ at $0-3,0-8,2.5-5.5$ and 5-8 $\mathrm{h}$ after infection or were left untreated as a control. Biogenesis of the replication vacuole of $W$. chondrophila but not that of $P$. acanthamoebae was inhibited significantly when macrophages were treated with BFA from 0 to $8 \mathrm{~h}$ or from 2.5 to $5.5 \mathrm{~h}$ and, to a lesser extent, from 5 to $8 \mathrm{~h}$. The number of bacteria per infected macrophage was counted following immunofluorescence detection at $8 \mathrm{~h}$ post-infection as described in Methods. Data represent means \pm SD of triplicates of one representative experiment performed three times independently. (b) Mitochondrial recruitment to BCVs and bacterial growth are only inhibited by simultaneous disruption of microtubules and actin filaments with nocodazole and cytochalasin D. Percentages of bacteria enclosed in vacuoles that positively co-localize with MitoTracker CMXRos at 8 h post-infection and the number of bacteria per infected macrophage at $8 \mathrm{~h}$ post-infection following immunofluorescence detection are shown, as described in Methods (note that the vertical axis does not start at 0 ). Human macrophages infected with $W$. chondrophila were treated from 0 to $8 \mathrm{~h}$ with $20 \mu \mathrm{M}$ nocodazole (Noco) or $10 \mu \mathrm{M}$ cytochalasin D (CytoD) separately without affecting mitochondrial recruitment to BCVs or bacterial growth significantly. However, simultaneous treatment of macrophages with $20 \mu \mathrm{M}$ nocodazole and $10 \mu \mathrm{M}$ cytochalasin $\mathrm{D}$ from 0 to $8 \mathrm{~h}$ abolished both mitochondrial recruitment and bacterial growth completely. Recruitment of mitochondria and bacterial growth could be inhibited immediately during infection upon treatment with nocodazole plus cytochalasin D, as shown for incubation times 3-8 and 5-8 h. Mitochondrial recruitment and bacterial growth were recovered when nocodazole plus cytochalasin D were washed away after $3 \mathrm{~h}(0-3 \mathrm{~h})$ and $5 \mathrm{~h}(0-5 \mathrm{~h})$ treatment. Untreated macrophages were used as controls. The final DMSO concentration was $0.1 \%$ in macrophages treated with one drug at a time and $0.2 \%$ during simultaneous drug treatment. When not indicated, the time of incubation is $0-8 \mathrm{~h}$. Data represent means \pm SD from one of three independent experiments assayed in duplicate. 


\section{DISCUSSION}

The obligate intracellular bacterium $W$. chondrophila replicates efficiently within amoebae (Michel et al., 2004), McCoy cells (Henning et al., 2002), bovine turbinate cells, P388D1 mouse macrophages (Kocan et al., 1990) and monocyte-derived human macrophages (Goy et al., 2008). However, the mechanisms used by these bacteria to evade host-defence mechanisms and to establish an intracellular replication niche are unknown. In this study, we analysed the early intracellular trafficking of $W$. chondrophila in monocyte-derived human macrophages during the first hours of cell invasion and demonstrated that $W$. chondrophila evades the phagocytic pathway, recruits mitochondria to the BCVs and co-localizes with ER (Fig. 9).

All vacuoles containing live or heat-inactivated $W$. chondrophila and $P$. acanthamoebae transiently acquired the early endosomal marker EEA1 during the first $30 \mathrm{~min}$ following uptake. This probably results either from recruitment of EEA1 from the cytosol or from fusion of the nascent vacuole with an early endosome. The presence

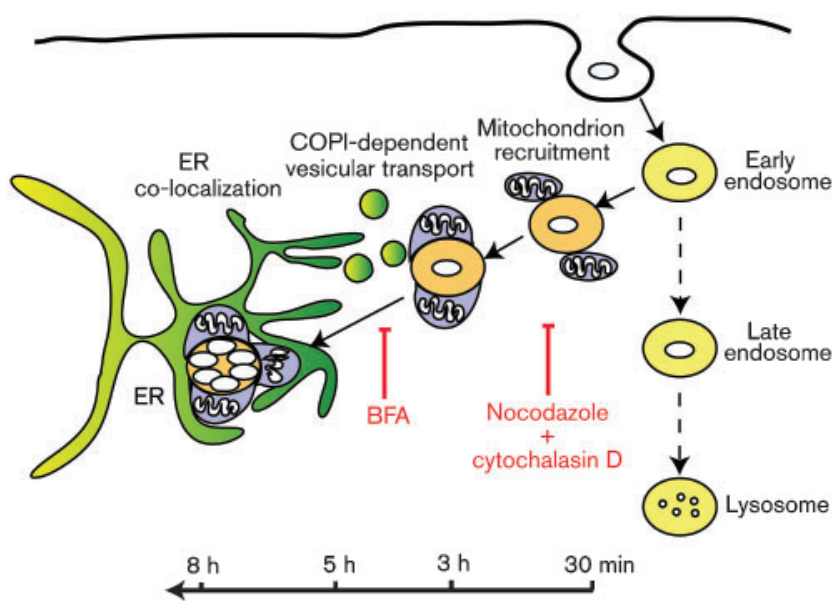

Fig. 9. Model of intracellular trafficking of W. chondrophila within monocyte-derived human macrophages. After transient localization in early endosomes, W. chondrophila evades the endocytic pathway. Host-cell mitochondria are quickly recruited to the $\mathrm{BCV}$, as early as $30 \mathrm{~min}$ post-infection, to form an intimate association with the $W$. chondrophila inclusion membrane. Mitochondrial recruitment to BCVs and bacterial growth are inhibited when both microtubules and actin filaments are disrupted simultaneously with nocodazole and cytochalasin D. From about 2.5 to $5.5 \mathrm{~h}$ post-infection, COPI-dependent vesicular trafficking from the ER is required transiently for the proper maturation of the BCV into an organelle that can sustain bacterial replication. BFA treatment of macrophages during that period of infection efficiently inhibits bacterial replication. A significant increase in co-localization of $W$. chondrophila inclusions with the ER markers calnexin, $\mathrm{PDI}$ and KDEL is observed between 5 and $8 \mathrm{~h}$ post-infection. At $8 \mathrm{~h}$ after bacterial uptake, mature $W$. chondrophila replicative vacuoles intimately associated with mitochondria co-localize with the ER. of EEA1 on the membrane of the three different BCVs suggests that the mechanism of entry is probably similar for the live $W$. chondrophila, the heat-inactivated $W$. chondrophila and for $P$. acanthamoebae. This is in agreement with studies performed on several Chlamydia species that have shown that the determinants that trigger internalization are intrinsic to the EB outer membrane, since de novo protein synthesis by the bacterium is not required, and $\mathrm{EB}$ outer membrane ghosts are internalized as efficiently as live bacteria (Eissenberg et al., 1983; Friis, 1972; Scidmore et al., 1996).

Instead of interacting with the endosomal pathway, $W$. chondrophila co-localizes immediately with the mitochondrial marker MitoTracker and, shortly after, with several ER-resident proteins such as calnexin and PDI. The fact that, in contrast to $P$. acanthamoebae, $W$. chondrophila evades the endocytic pathway and traffics to the ER may explain why $W$. chondrophila is often localized in dense ER regions distributed at the periphery of the cell or around the nucleus. The co-localization with mitochondria and ER markers coincides with the initiation of the reproductive phase of the bacterial life cycle that occurs at $5 \mathrm{~h}$ postinfection. Hence, the association of the W. chondrophila vacuoles with mitochondria and the ER probably represents a prerequisite for the maturation of the vacuole to a stage that supports bacterial replication.

Similarly to $W$. chondrophila, the vacuolar membrane of some Chlamydia psittaci strains forms intimate associations with host mitochondria, probably mediated by chlamydial proteins localizing to the host-cell side of the inclusion membrane (Matsumoto et al., 1991). The initiation of mitochondrial recruitment to $C$. psittaci inclusions coincides with the initiation of bacterial replication and is mediated by kinesin-dependent mitochondrial movement along microtubules (Matsumoto et al., 1991). The parasitophorous vacuole membrane (PVM) of the protist Toxoplasma gondii also forms a tight association with host mitochondria and the ER soon after invasion (Sinai et al., 1997). Interestingly, treatment with the microtubuledepolymerizing agent nocodazole inhibits the establishment but not the maintenance of mitochondrial association with the $T$. gondii PVM. The tight and specific association of organelles with the T. gondii PVM indicates strongly that a stable and high-affinity protein-protein interaction is the basis of the intermolecular mechanisms that regulate both the establishment and the maintenance of the association (Sinai et al., 1997).

Unlike mitochondrial recruitment by $C$. psittaci and $T$. gondii, which relies mainly on the microtubule network, $W$. chondrophila uses two alternative mitochondrial recruitment pathways via microtubules and/or actin filaments. The integrity of only one of the cytoskeleton structures is sufficient to permit mitochondrial recruitment by $W$. chondrophila, and it is only when both cytoskeletal systems are disrupted that the recruitment of organelles and bacterial growth cease. These results are consistent with 
several publications showing that either microtubules or actin filaments are sufficient for transport of mitochondria in various cell types (Frederick \& Shaw, 2007; Morris \& Hollenbeck, 1995). The percentage of MitoTracker-positive BCVs observed under the different drug treatment conditions tested directly correlates with the growth of $W$. chondrophila, suggesting that only bacterial inclusions that have established an intimate interaction with mitochondria prior to drug treatment can sustain bacterial growth. Interestingly, members of the Chlamydiales are true energy parasites that are dependent on the host cell for ATP and other high-energy metabolites (McClarty, 1994; Moulder, 1991). Members of the Chlamydiales encode an ATP/ADP translocase that exploits the host ATP pool (Greub \& Raoult, 2003; Horn et al., 2004; Stephens et al., 1998). We have also identified a similar ATP/ADP translocase in W. chondrophila (GenBank accession no. AY851747). Thus, mitochondrial association with bacterial inclusions represents a potential mechanism to scavenge ATP from a highly concentrated pool of ATP in the vicinity of the BCVs. Interestingly, several studies indicate that mitochondria are enriched at sites of high ATP use in a wide variety of cell types (Chada \& Hollenbeck, 2004; Frederick \& Shaw, 2007; Hollenbeck \& Saxton, 2005) by a mechanism that involves both actin and microtubules. Thus, W. chondrophila inclusions could also benefit from normal mitochondrial distribution in host cells simply by establishing a site of high ATP use.

Chlamydia species traffic to the Golgi area and intercept vesicular traffic from the Golgi to the plasma membrane to scavenge host sphingolipids, and presumably other lipids, that are delivered in the bacterial vesicles and incorporated into the membrane of replicating RBs (Hackstadt et al., 1995). The association of W. chondrophila with mitochondria and the ER could also be explained as an alternative strategy developed by the bacterium to scavenge lipids from host cells. Indeed, both mitochondria and the ER are involved in lipid metabolism in mammalian cells (Trotter \& Voelker, 1994). Sites of membrane continuity between mitochondria and the ER are involved in lipid transfer between these organelles (Vance \& Shiao, 1996). A similar pathway, linking distinct cellular compartments by direct membrane contact, may be used as a mechanism of lipid trafficking to the $\mathrm{BCV}$ at sites of associated organelles. Thus, lipids and other nutrients could be delivered to the $W$. chondrophila inclusion either by vesicular traffic, as seen from the chlamydial inclusion (Hackstadt et al., 1995), or by direct translocation from associated ER and mitochondria. Furthermore, the study by Pitts et al. (1999) demonstrated that mitochondria and the ER share at least one dynamin-like protein involved in their morphology and distribution. The physical and functional interactions between mitochondria and ER suggest that co-localization of $W$. chondrophila with the ER could be an indirect consequence of mitochondrial recruitment or that the bacteria target proteins shared by both mitochondria and the ER that are involved in intracellular vesicular trafficking or in physical interorganelle interactions.

Mature W. chondrophila replicative BCVs, like those of $L$. pneumophila and B. abortus, co-localize with the ER. However, the nature of the $W$. chondrophila BCV-ER association remains to be determined. The biogenesis of the L. pneumophila ER-derived organelle depends on rapid interception of COPI-dependent vesicular trafficking from ER exit sites (Kagan \& Roy, 2002) and can be blocked with BFA, whereas blocking such trafficking does not affect the biogenesis of the B. abortus replicative vacuole (Celli \& Gorvel, 2004). Similar to L. pneumophila, the growth of $W$. chondrophila can be inhibited partially with BFA when the macrophages are treated during a short period, between 2 and $5 \mathrm{~h}$ post-infection, which probably represents a critical phase of organelle maturation corresponding precisely to a pre-replication stage of vacuole biogenesis. These data suggest that nutrient acquisition by the maturating $\mathrm{BCV}$ may occur by several routes, including COPI-dependent vesicular trafficking from ER exit sites and transfer via regions of membrane continuity between host organelles and the BCVs. However, it is also possible that BFA treatment could impact indirectly on the replication of $W$. chondrophila by affecting other cellular mechanisms than ER-Golgi vesicular trafficking. Thus, BFA treatment represents only indirect evidence of the interactions between $W$. chondrophila-containing vacuoles and the ER.

The replication of $W$. chondrophila in association with the mitochondria and ER of human macrophages represents a novel route for intracellular trafficking amongst species of the Chlamydiales and differs from all other members of the Chlamydiaceae (Hackstadt et al., 1995) and Parachlamydiaceae (Greub et al., 2005). Even though the development cycle is a trait conserved in all known members of the Chlamydiales, there are significant differences in development stages, subcellular location and mechanisms of resistance against host-cell defences. The molecular mechanisms developed by the bacterium to evade the endocytic pathway and to modulate the vesicle fusion mechanisms of the host cell remain to be determined.

Future experiments are required to understand better how this member of the Chlamydiales is able to evade the phagocytic pathway and to establish a replicative niche in association with mitochondria and the ER. Finally, the benefits to the bacterium of such an association remain to be determined.

\section{ACKNOWLEDGEMENTS}

This study was supported by the State Secretary for Education and Research, Berne, Switzerland (project no. C06.0100), as part of European Cooperation in the Field of Scientific and Technical Research Action 855. We thank J. L. Barblan (Department of Fundamental Microbiology, Lausanne, Switzerland) and the PFMU at the Medical Faculty of Geneva for assisting with electron microscopy analyses as well as the Cellular Imaging Facility platform of the 
University of Lausanne for confocal microscopy. G. G. is supported by the Leenards Foundation through a career award entitled 'Bourse Leenards pour la relève académique en médecine clinique à Lausanne'.

\section{REFERENCES}

Bandyopadhyay, P., Liu, S., Gabbai, C. B., Venitelli, Z. \& Steinman, H. M. (2007). Environmental mimics and the Lvh type IVA secretion system contribute to virulence-related phenotypes of Legionella pneumophila. Infect Immun 75, 723-735.

Baud, D., Thomas, V., Arafa, A., Regan, L. \& Greub, G. (2007). Waddlia chondrophila, a potential agent of human fetal death. Emerg Infect Dis 13, 1239-1243.

Bellaire, B. H., Roop, R. M., II \& Cardelli, J. A. (2005). Opsonized virulent Brucella abortus replicates within nonacidic, endoplasmic reticulum-negative, LAMP-1-positive phagosomes in human monocytes. Infect Immun 73, 3702-3713.

Boldogh, I. R. \& Pon, L. A. (2006). Interactions of mitochondria with the actin cytoskeleton. Biochim Biophys Acta 1763, 450-462.

Capo, C., Zugun, F., Stein, A., Tardei, G., Lepidi, H., Raoult, D. \& Mege, J. L. (1996). Upregulation of tumor necrosis factor alpha and interleukin-1 beta in Q fever endocarditis. Infect Immun 64, 1638-1642.

Casson, N., Medico, N., Bille, J. \& Greub, G. (2006). Parachlamydia acanthamoebae enters and multiplies within pneumocytes and lung fibroblasts. Microbes Infect 8, 1294-1300.

Celli, J. \& Gorvel, J. P. (2004). Organelle robbery: Brucella interactions with the endoplasmic reticulum. Curr Opin Microbiol 7, 93-97.

Celli, J., de Chastellier, C., Franchini, D. M., Pizarro-Cerda, J., Moreno, E. \& Gorvel, J. P. (2003). Brucella evades macrophage killing via VirB-dependent sustained interactions with the endoplasmic reticulum. J Exp Med 198, 545-556.

Chada, S. R. \& Hollenbeck, P. J. (2004). Nerve growth factor signaling regulates motility and docking of axonal mitochondria. Curr Biol 14, 1272-1276.

Corsaro, D. \& Greub, G. (2006). Pathogenic potential of novel Chlamydiae and diagnostic approaches to infections due to these obligate intracellular bacteria. Clin Microbiol Rev 19, 283-297.

Dilbeck-Robertson, P., McAllister, M. M., Bradway, D. \& Evermann, J. F. (2003). Results of a new serologic test suggest an association of Waddlia chondrophila with bovine abortion. J Vet Diagn Invest 15, 568-569.

Duclos, S. \& Desjardins, M. (2000). Subversion of a young phagosome: the survival strategies of intracellular pathogens. Cell Microbiol 2, 365-377.

Eissenberg, L. G., Wyrick, P. B., Davis, C. H. \& Rumpp, J. W. (1983). Chlamydia psittaci elementary body envelopes: ingestion and inhibition of phagolysosome fusion. Infect Immun 40, 741-751.

Everett, K. D., Bush, R. M. \& Andersen, A. A. (1999). Emended description of the order Chlamydiales, proposal of Parachlamydiaceae fam. nov. and Simkaniaceae fam. nov., each containing one monotypic genus, revised taxonomy of the family Chlamydiaceae, including a new genus and five new species, and standards for the identification of organisms. Int J Syst Bacteriol 49, 415-440.

Frederick, R. L. \& Shaw, J. M. (2007). Moving mitochondria: establishing distribution of an essential organelle. Traffic 8, 1668-1675.

Friis, R. R. (1972). Interaction of L cells and Chlamydia psittaci: entry of the parasite and host responses to its development. J Bacteriol 110, 706-721.

Goy, G., Croxatto, A. \& Greub, G. (2008). Waddlia chondrophila enters and multiplies within human macrophages. Microbes Infect 10, 556-562.
Greub, G. \& Raoult, D. (2002). Crescent bodies of Parachlamydia acanthamoeba and its life cycle within Acanthamoeba polyphaga: an electron micrograph study. Appl Environ Microbiol 68, 3076-3084.

Greub, G. \& Raoult, D. (2003). History of the ADP/ATP-translocaseencoding gene, a parasitism gene transferred from a Chlamydiales ancestor to plants 1 billion years ago. Appl Environ Microbiol 69, 5530-5535.

Greub, G., Mege, J. L., Gorvel, J. P., Raoult, D. \& Meresse, S. (2005). Intracellular trafficking of Parachlamydia acanthamoebae. Cell Microbiol 7, 581-589.

Hackstadt, T., Scidmore, M. A. \& Rockey, D. D. (1995). Lipid metabolism in Chlamydia trachomatis-infected cells: directed trafficking of Golgi-derived sphingolipids to the chlamydial inclusion. Proc Natl Acad Sci U S A 92, 4877-4881.

Henning, K., Schares, G., Granzow, H., Polster, U., Hartmann, M., Hotzel, H., Sachse, K., Peters, M. \& Rauser, M. (2002). Neospora caninum and Waddlia chondrophila strain 2032/99 in a septic stillborn calf. Vet Microbiol 85, 285-292.

Hollenbeck, P. J. \& Saxton, W. M. (2005). The axonal transport of mitochondria. J Cell Sci 118, 5411-5419.

Horn, M. (2008). Chlamydiae as symbionts in eukaryotes. Annu Rev Microbiol 62, 113-131.

Horn, M., Collingro, A., Schmitz-Esser, S., Beier, C. L., Purkhold, U., Fartmann, B., Brandt, P., Nyakatura, G. J., Droege, M. \& other authors (2004). Illuminating the evolutionary history of chlamydiae. Science 304, 728-730.

Kagan, J. C. \& Roy, C. R. (2002). Legionella phagosomes intercept vesicular traffic from endoplasmic reticulum exit sites. Nat Cell Biol 4, 945-954.

Kocan, K. M., Crawford, T. B., Dilbeck, P. M., Evermann, J. F. \& McGuire, T. C. (1990). Development of a rickettsia isolated from an aborted bovine fetus. J Bacteriol 172, 5949-5955.

Ligon, L. A. \& Steward, O. (2000). Role of microtubules and actin filaments in the movement of mitochondria in the axons and dendrites of cultured hippocampal neurons. J Comp Neurol 427, 351-361.

Matsumoto, A., Bessho, H., Uehira, K. \& Suda, T. (1991). Morphological studies of the association of mitochondria with chlamydial inclusions and the fusion of chlamydial inclusions. J Electron Microsc (Tokyo) 40, 356-363.

McClarty, G. (1994). Chlamydiae and the biochemistry of intracellular parasitism. Trends Microbiol 2, 157-164.

Mege, J. L., Sanguedolce, M. V., Jacob, T., Bongrand, P., Capo, C., Myssiakine, E. B. \& Barot-Ciorbaru, R. (1993). Nocardia fractions, NLD and NWSM, induce tumor necrosis factor-alpha secretion in human monocytes: role of protein kinase C. Eur J Immunol 23, 15821587.

Michel, R., Steinert, M., Zöller, L., Hauröder, B. \& Henning, K. (2004). Free-living amoebae may serve as hosts for the Chlamydia-like bacterium Waddlia chondrophila isolated from an aborted bovine foetus. Acta Protozool 43, 37-42.

Morris, R. L. \& Hollenbeck, P. J. (1995). Axonal transport of mitochondria along microtubules and F-actin in living vertebrate neurons. J Cell Biol 131, 1315-1326.

Moulder, J. W. (1991). Interaction of chlamydiae and host cells in vitro. Microbiol Rev 55, 143-190.

Pitts, K. R., Yoon, Y., Krueger, E. W. \& McNiven, M. A. (1999). The dynamin-like protein DLP1 is essential for normal distribution and morphology of the endoplasmic reticulum and mitochondria in mammalian cells. Mol Biol Cell 10, 4403-4417.

Roy, C. R. \& Tilney, L. G. (2002). The road less traveled: transport of Legionella to the endoplasmic reticulum. J Cell Biol 158, 415-419. 
Rurangirwa, F. R., Dilbeck, P. M., Crawford, T. B., McGuire, T. C. \& McElwain, T. F. (1999). Analysis of the $16 \mathrm{~S}$ rRNA gene of microorganism WSU 86-1044 from an aborted bovine foetus reveals that it is a member of the order Chlamydiales: proposal of Waddliaceae fam. nov., Waddlia chondrophila gen. nov., sp. nov. Int J Syst Bacteriol 49, 577-581.

Scidmore, M. A., Rockey, D. D., Fischer, E. R., Heinzen, R. A. \& Hackstadt, T. (1996). Vesicular interactions of the Chlamydia trachomatis inclusion are determined by chlamydial early protein synthesis rather than route of entry. Infect Immun 64, 5366-5372.

Sinai, A. P., Webster, P. \& Joiner, K. A. (1997). Association of host cell endoplasmic reticulum and mitochondria with the Toxoplasma gondii parasitophorous vacuole membrane: a high affinity interaction. J Cell Sci 110, 2117-2128.
Stephens, R. S., Kalman, S., Lammel, C., Fan, J., Marathe, R., Aravind, L., Mitchell, W., Olinger, L., Tatusov, R. L. \& other authors (1998). Genome sequence of an obligate intracellular pathogen of humans: Chlamydia trachomatis. Science 282, 754-759.

Trotter, P. J. \& Voelker, D. R. (1994). Lipid transport processes in eukaryotic cells. Biochim Biophys Acta 1213, 241-262.

Vance, J. E. \& Shiao, Y. J. (1996). Intracellular trafficking of phospholipids: import of phosphatidylserine into mitochondria. Anticancer Res 16, 1333-1339.

Via, L. E., Fratti, R. A., McFalone, M., Pagan-Ramos, E., Deretic, D. \& Deretic, V. (1998). Effects of cytokines on mycobacterial phagosome maturation. J Cell Sci 111, 897-905.

Edited by: K. Fields 